\title{
22nd Annual Meeting of the International Society of Blood Purification (ISBP)
}

Keynote Lecture and Abstracts

September 3-5, 2004, London

Editors

Andrew Davenport, London

Pamela Fong Francis, London

\section{Contents}

Keynote Lecture

Haemodiafiltration

Abstracts 1-14

381

Haemodialysis

Abstracts 15-38

386

Oxidative Stress

Abstracts $39-47$

395

Peritoneal Dialysis

Abstracts

48-53

398

Liver Failure Therapy

Abstracts 54-64

401

Author Index 


\section{Transplantation: From the Past to the Future}

\author{
P.J. Morris
}

Emeritus Professor of Surgery, University of Oxford, Royal College of Surgeons of England, UK

The history of transplantation dates back for just on 100 years. In Vienna in 1902, Ullman performed an experimental kidney transplant in a dog, the kidney being implanted in the neck [1]. Allegedly it did function briefly, at least long enough for the animal to be displayed at a medical meeting on the evening of the transplant. The first human transplant was performed by Jaboulay, Professor of Surgery in Lyon, in 1906 [2]. In two procedures he connected a sheep and a pig kidney, respectively, to the arm vessels of patients suffering from acute renal failure. Neither kidney functioned. However, this had been made possible by the research work of a young surgeon in Jaboulay's team, Alexis Carrel, around the turn of the century. Carrel had worked for some years on methods of joining vessels together, and in 1902 he had published his landmark paper describing the technique of an end-to-end anastomosis of an artery as well as the use of this technique to implant a kidney in the neck of a dog [3]. Later he was to describe the end-to-side anastomosis using a patch, now known as a Carrel patch. It is interesting that these techniques are exactly the same today over 100 years later!

Carrel was to move to Chicago and then the Rockefeller Institute in New York where he performed large numbers of experimental transplants in animals, leading him to eventually state that the techniques of organ transplantation had been resolved, but until one could prevent the inflammatory action which destroyed the organs after a week or so, there was no immediate clinical application. However, in a remarkable lecture given in 1914 to the International Surgical Society, he said that the development of anti-cancer therapy which was proceeding at the Rockefeller Institute might provide such a method in the not too distant future [4]. Of course, it was some 50 years before that was to occur.

Several attempts were made to transplant kidneys in humans predominantly by Voronoy in Russia before the Second World War, and several groups had also explored further experimental kidney transplantation in animals [5]. However, the modern era of transplantation began with David Hume, a young surgeon at the Peter Bent Brigham Hospital, who in the late 1940s carried out a small series of cadaver kidney transplants without any form of immunosuppression in patients dying of renal failure [6]. The kidneys were implanted in the thigh with the renal vessels anastomosed to the femoral vessels and the ureter brought out on the skin as a ureterostomy. Although no immunosuppression was used, the severe uraemia present in these patients did lead to a degree of immunosuppression, and some of these kidneys functioned for several weeks.

An enormous effort was then devoted to using total body irradiation as a form of immunosuppression during the 1950s both in Paris and in Boston. Two other major events occurred in the 1950s; the first was the landmark paper by Billingham, Brent and Medawar in which they described the induction of the neonatal tolerance in mice, thus confirming the hypothesis advanced by Burnet that recognition of self developed in the foetus in utero [7]. The second major event was again in 1953; Murray, Merrill and Harrison performed a transplant between identical twins in Boston [8]. On this occasion the kidney was implanted in the iliac fossa, in the same way as practised today, a technique first described by Kuss in Paris. The operation was technically successful and the kidney functioned normally which, it has to be said, was uncertain at that time as no one was sure whether a denervated kidney would function in a normal physiological manner despite the lack of any rejection reaction.

In the late 1950s, Elion and Hitchings had developed an anti-cancer agent 6-mercaptopurine, which the clinical haematologists Schwartz and Dameschek showed to be immunosuppressive, and their description of drug induced immunological tolerance in Nature in 1958 was another landmark paper $[9,10]$. This paper was noted by Calne in the UK and Zukoski and Hume in the USA, and they were able to then demonstrate that 6-mercaptopurine would prolong the survival of kidney allografts in dogs $[11,12]$. Elion and Hitchings had by then developed a parent compound of 6-mercaptopurine, azathioprine, which was perhaps less toxic than 6-mercaptopurine and by the mid1960 s this had been introduced into clinical practice.

Azathioprine combined with high doses of steroids became the standard immunosuppressive therapy and there was an explosion in the number of kidney transplants performed. By 1968, one-year graft survivals of around $60 \%$ were being obtained, but patient mortality at 1 year ranged from $20 \%$ to nearly $40 \%$, mostly due to the side effects of the immunosuppressive drugs. A randomised controlled trial of lowdose steroids in Oxford confirmed the initial observations of Mollie McGowan that low-dose steroids were equally effective as high-dose steroids in the prevention of rejection, but led to a remarkable decrease in the incidence of the side effects of immunosuppressive drug therapy, most of which were due to the high-dose steroids [13]. Azathioprine with low-dose steroids then became the routine immunosuppressive regimen, with rejection being treated by a short course of high oral dose steroids or intravenous boluses of methylprednisolone.

By the end of the 1960s the major histocompatibility system in man, HLA, had been recognised, albeit at a crude level, and there was now evidence that matching for a limited number of antigens detected at that time seemed to be associated with better cadaveric graft survival [14]. During the 1970s the HLA system and its genetic control were further defined and matching, where possible, became the normal practice in renal transplantation. It was also recognised that the major benefit of matching for HLA was obtained from matching for HLA-DR [15]. Furthermore, it had been recognised in the late 1960s that cytotoxic antibodies occurred after transplantation and that transplantation in the presence of such antibodies reacting with the donor would lead to hyper-acute rejection $[16,17]$. Thus a positive crossmatch between donor lymphocytes and sera from the potential recipient became a contraindication to renal transplantation. Again in the late 1960 s the first heart transplant was performed and also the first

\section{KARGER}

Fax +41613061234

E-Mail karger@karger.ch

www.karger.com 
liver transplant $[18,19]$. In both cases initial results were poor, especially in liver transplantation. Pancreas, lung and combined heart and lung transplantation also evolved in the 1970s.

Again in the late 1960s Belzer and colleagues had developed machine preservation of kidneys in dogs for up to 72 hours, and this was quickly applied to clinical practice [20]. Shortly after this development, initial perfusion of the kidney with solutions with an intracellular electrolyte composition followed by storage in ice was shown to be effective also, and this method was to replace machine preservation in most centres over the next few years [21].

The next major advance in transplantation was the introduction of cyclosporine into the clinical arena. The immunosuppressive properties of this antifungal agent had been discovered by Borel, an immunologist working with Sandoz, and it was first introduced into clinical practice in kidney transplantation by Calne at Cambridge [22, 23]. By 1983 it had become the drug of choice in North America and Europe, but its expense prohibited its use in poorer countries except on a rather limited basis. Again its side effects, particularly nephrotoxicity, led to the development of a number of protocols which would allow its immunosuppressive potency to be maintained while reducing its side effects. Very quickly so called triple therapy (low-dose cyclosporine, azathiaprine and steroids) became the most commonly used protocol [24]. This resulted in a marked reduction in loss of kidneys from acute irreversible rejection within the first six months after transplant, and thus a much better 1-year graft survival which soon, in most units, was now over $80 \%$.

Newer immunosuppressive drugs have subsequently been introduced such as tacrolimus (like cyclosporine, a calcineurin inhibitor) and newer antiproliferative agents such as mycophenolate mofetil and sirolimus. Similarly a number of biological anti-lymphocyte agents have been developed in an attempt to replace the polymorphic antilymphocyte and anti-thymocyte agents that had been in use for some years [25]. Today the most commonly used biological agent is a monoclonal antibody directed against the interleukin-2 receptor. All of these new agents are used in combination and have led to a further reduction in the incidence of acute rejection during the first six months but it is not clear that this has led to better 1-year graft survival or indeed better longer-term survival, although this may prove to be the case. Similarly the results of cardiac and liver transplantation changed dramatically after the introduction of cyclosporine and even more so with the introduction of some of the newer immunosuppressive agents, so that 5-year graft survival after liver transplantation is around $70 \%$ and after cardiac transplantation around 60-70\% [26, 27].

However, numerous complications still occur after transplantation and many of these complications are becoming far more evident with the increasing long-term survival of patients after transplantation. Furthermore, chronic rejection in all organs remains a major cause of graft loss in the long term, and for this there is no current therapy. It is hoped that the new anti-proliferative immunosuppressive agents such as mycophenolate and sirolimus may reduce the incidence of chronic rejection.

In the future there are a number of avenues that will continue to be explored. The first is the induction of tolerance to an organ allograft. In the experimental animal, especially the rodent, tolerance can be achieved via a variety of techniques and some of these have proved successful in larger animal models including primate models [28]. However, at this moment the protocols which have allowed tolerance to be induced in large animals are too severe to be applicable in general clinical practice. Nevertheless, it seems reasonable to suggest that tolerance will be achieved in clinical practice in the not too distant future.
Another major endeavour is in the area of xenotransplantation where the pig is the favoured donor animal [29]. There are a number of barriers to xenotransplantation, not the least being the presence of cytotoxic antibodies in man directed against the gal antigen expressed in all species except in the higher-order primates. Thus transplantation of a pig kidney, for example, into man would result in hyperacute rejection of that organ. However, the development of transgenic pigs expressing human complement inhibitors as well as knock-out pigs for the gal antigen have probably resolved this problem. Nevertheless we still do not know whether acute vascular rejection will be easily overcome and certainly chronic rejection is bound to be a major problem. However, the major concern which is preventing any clinical trials is the risk of the transmission of porcine retrovirus into the human recipient, and until this issue is resolved clinical trials are unlikely to occur.

Finally the development of stem cell technology, including nuclear replacement technology, does hold out the hope of producing successful transplants of tissues, such as insulin-producing beta cells, and perhaps even one day the development of tissue-engineered organs [30]. Despite the widespread enthusiasm surrounding this whole area of research it is probably some way off successful clinical application.

Transplantation has made remarkable strides over the last 40 years and I have no doubt that the next 20-30 years will see even more remarkable advances in this field. Furthermore it seems unlikely that many of the conditions leading to end-stage organ failure will be preventable in the near future.

\section{References}

1 Ullmann E: Experimentelle Nierentransplantion. Wien Klin Wochenschr 1902;15:281

2 Jaboulay M: Greffe de reins au pli du coude par soudure arte. Bull Lyon Med 1906;107:575.

3 Carrel A: La technique operatoire des anastomoses vasculaires et la transplantation des visceres. Lyon Med 1902;98:859.

4 Carrel A: The transplantation of organs. NY Med J 1914;99:389.

5 Hamilton D: Kidney transplantation: A History in kidney transplantation: Principles and Practice, 5th ed. Philadelphia, W B Saunders, 2001; pp 1-8.

6 Hume DM, Merrill JP, Miller BF, Thorn GW: Experiences with renal homotransplantation: Report of nine cases. J Clin Invest 1955;34: 327-382

7 Billingham R, Brent L, Medawar PB: Actively acquired tolerance of foreign cells. Nature 1953;172:603.

8 Murray JE, Merrill JP, Harrison JH: Kidney transplantation between seven pairs of identical twins. Ann Surg 1958;148:343.

9 Elion EB, Burgi E, Hitchings G: Studies on condensed pyrimidene systems: IX. Synthesis of some six-substituted purines. J AM Chem Soc $1952 ; 74: 411$

10 Schwartz R, Dameschek W: Drug-induced immunological tolerance. Nature 1959;183:1682.

11 Calne RY: The rejection of renal homografts: Inhibition in dogs by 6 mercapto-purine. Lancet 1960;1:417.

12 Zukoski CF, Lee HM, Hume DM: The effect of 6-mercaptopurine on renal homograft survival in the dog. Surg Forum 1960;11:47.

13 Morris PJ, Chan L, French ME, Ting A: Low dose oral prednisolone in renal transplantation. Lancet 1982;1:525.

14 Terasaki PI, Marchioro TL, Starzl TE: In Histocompatibility Testing. (Amos DB and van Rood JJ, eds), National Academy of Sciences, Washington, 1965, p 83.

15 Ting A, Morris PJ: Matching for B-cell antigens of the HLA-DR (D-related) series in cadaver renal transplantation. Lancet 1978;1:575.

16 Morris PJ, Williams GM, Hume DM, Mickey MR, Terasaki PI: Serotyping for homotransplantations: XII. Occurrence of cytotoxic antibodies following kidney transplantation in man. Transplantation 1968; $6: 392$. 
17 Patel R, Terasaki PI: Significance of positive cross-match test in kidney transplantation. N Engl J Med 1969;280:735.

18 Barnard CN: The operation. A human cardiac transplant: An interim report of a successful operation performed at Groote Schuur Hospital Cape Town. S Afr Med J 1967;41:1271-1274.

19 Starzl TE, Marchiori TL, von Kaulla G, Hermann RS, et al: Homotransplantation of the liver in humans. Surg Gynecol Obstet 1963;117: L659-L676

20 Belzer FO, Asby BS, Dunphy JS: 24-Hour and 72-hour preservation of canine kidneys. Lancet 1967;2:536.

21 Collins GM, Bravo-Shugarman M, Terasaki PI: Kidney preservation for transportation: Initial perfusion and 30 hours' ice storage. Lancet 1969; 2:1219.

22 Borel JF: Comparative study of in vitro and in vivo drug effects on cell mediated cytotoxicity. Immunology 1976;31:631.

23 Calne RY, White DJG, Thiru S, et al: Cyclosporin A in patients receiving renal allografts from cadaver donors. Lancet 1978;2:1323.
24 Morris PJ: Cyclosporine in kidney transplantations; in Morris PJ (ed): Principles and Practice, 5th ed. Philadelphia, W B Saunders, 2001, pp 227-249.

25 Morris PJ: Kidney transplantations: Principles and Practice, 5th ed. Philadelphia, W B Saunders, 2000.

26 Dec GW: Cardiac transplantation; in Ginns LG, Cosimi AB, Morris PJ (eds): Transplantation. Boston, Blackwell Science, 1999, pp 438-473.

27 Powelson JA, Cosimi AB: Liver transplantation; in Ginns LG, Cosimi AB, Morris PJ (eds): Transplantation. Boston, Blackwell Science, 1999, pp 324-373.

28 Wood KJ: Approaches to the induction of tolerance; in Morris PJ (ed): Kidney Transplantation: Principles and Practice, 5th ed. Philadelphia, W B Saunders, 2001, pp 326-341.

29 Soin R, Friend PJ: Renal xenotransplantation; in Morris PJ (ed): Kidney Transplantation: Principles and Practice, 5th ed. Philadelphia, W B Saunders, 2001.

30 Gurdon JB, Colman A: The future of cloning. Nature 1999;402:743. 


\section{Haemodiafiltration}

\section{1}

\section{On-Line Hemodiafiltration (HDF) with High Volume Substitution Fluid: Long Term Efficacy and Security}

\author{
1. Aires, P. Matias, C. Gil, C. Jorge, A. Ferreira \\ Hemodial, Vila Franca de Xira, Portugal
}

We evaluated the efficacy and security of on-line HDF (HDF$250)$ with high substitution fluid load $(250 \mathrm{ml} / \mathrm{min} ; 60 \mathrm{~L} / \mathrm{session})$, in haemodialysed (HD) patients, during 12 months by evaluating removal of small (urea eKt/V), middle molecules (serum $\beta 2$-microglobulin) and heavy metals (aluminium). The effects on inflammatory markers (CRP) and serum albumin were analysed 3 monthly. During the 12 months (T0, T3, T6, T9, T12) 29 chronic HD patients (19 male, mean age $54.1 \pm 13.1$ years) submitted to HDF-250 (2 were transplanted) were studied. These patients were compared to a control group of 28 high-flux haemodialysed patients (HF). Exclusion criteria: infectious and inflammatory diseases, non-steroid anti-inflammatory drugs and antibiotics. Every patient was dialysed with high- flux polysulfone dialyser, with ultra-pure water. The patients on HDF-250 revealed a significant reduction of the serum CRP from the onset of the technique, and maintained during the 12-month study (T0 = $0.95 \pm 0.73 \mathrm{mg} / \mathrm{dl} ; \mathrm{T} 3=0.59 \pm 0.19 \mathrm{mg} / \mathrm{dl}(\mathrm{p}=0.009) ; \mathrm{T} 6=0.67 \pm$ $0.38 \mathrm{mg} / \mathrm{dl}(\mathrm{p}=0.04) ; \mathrm{T} 9=0.65 \pm 0.45 \mathrm{mg} / \mathrm{dl}(\mathrm{p}=0.04) ; \mathrm{T} 12=$ $0.65 \pm 0.37 \mathrm{mg} / \mathrm{dl}(\mathrm{p}=0.04))$. There was no significant CRP variation for the HF group. Both techniques showed a significant and progressive serum aluminium reduction from $\mathrm{T} 0$ to $\mathrm{T} 12$. Beta2-microglobulin $(\mathrm{HDF}$ T0 $=17,283 \pm 6,518 \mathrm{ng} / \mathrm{ml} ; \mathrm{HDF}$ T12 = 16,355 \pm 4,944 ng $/ \mathrm{ml})$, albumin $(\mathrm{HDF}$ T0 $=3.96 \pm 0.31 \mathrm{~g} / \mathrm{dl} ; \mathrm{HDF}$ T12 $=4.0 \pm 0.37 \mathrm{~g} / \mathrm{dl}$ ) and $\mathrm{ekt} / \mathrm{v}(\mathrm{HDF} \mathrm{T} 0=1.44 \pm 0.21 ; \mathrm{HDF} \mathrm{T} 12=1.42 \pm 0.25)$ values remained stable during the whole study, with no significant difference between HDF-250 and HF. Our results reveal, for the first time on a long-term basis, that convection optimisation with high volume substitution loads (HDF-250) is a safe technique, associated with a reduction in serum inflammatory markers, without compromising the small molecule dialysis and the nutritional status of the dialysed patients.

\section{2 \\ Superior Dialytic Clearance of the Middle Molecule B2-Microglobulin and the Protein-Bound Solute P-Cresol during High Flux Hemodialysis as Compared to Peritoneal Dialysis}

\author{
P. Evenepoel, B. Bammens, K. Verbeke, \\ Y. Vanrenterghem \\ Internal Medicine, Division of Nephrolgy, \\ UZ Gasthuisberg, Laboratory of Digestion and \\ Absorption, UZ Gasthuisberg, The Netherlands
}

Background: Protein-bound solutes are increasingly recognized to be important uremic toxins. As for middle molecules (MM), their serum levels have been demonstrated to be higher in hemodialysis (HD) patients than in patients treated with continuous ambulatory peritoneal dialysis (CAPD). This finding is attributed to the fact that PD constitutes a continuous renal replacement therapy without the disadvantages of post-dialytic rebound and inter-dialytic toxin generation, which are characteristic for intermittent HD. The aim of the present study was to compare dialytic clearances of solutes with different characteristics between HD and CAPD patients. Methods: We performed a cross-sectional observational study including 14 stable patients ( 10 male, mean age $66.57 \pm 3.14$ years) treated with HD and 15 patients ( 8 male, mean age $51.53 \pm 3.50$ years) treated with CAPD. HD patients were dialyzed during three $4 \mathrm{~h}$ sessions per week with a high-flux polysulfone membrane (F80S). Blood flow was set at $350 \mathrm{~mL} / \mathrm{min}$ and dialysate flow at $500 \mathrm{~mL} / \mathrm{min}$. Serum levels of the water soluble solutes urea nitrogen $(\mathrm{UN})$, creatinine $(\mathrm{Cr})$ and phosphate $(\mathrm{Ph})$, the MM $\beta 2$-microglobulin $(\beta 2 \mathrm{M})$ and the protein-bound solute $\mathrm{p}$-cresol were measured before the mid-week session in HD patients and mid-day in CAPD patients. Total weekly dialytic solute clearances $(\mathrm{Cl}, \mathrm{L} /$ week) were calculated from total dialysate collection during the mid-week session in HD and $24 \mathrm{~h}$ dialysate collection in CAPD. Residual renal function (RRF) was assessed by the mean of renal $\mathrm{UN}$ and $\mathrm{Cr}$ clearances (RRF, $\mathrm{mL} / \mathrm{min}$ ). Comparisons between HD and CAPD were made by Student's t-tests or Wilcoxon rank sum test. P-values $<0.05$ were considered statistically significant. Results: The serum levels of all uremic solutes were lower in CAPD patients than in HD patients. Statistical significance, however, was not reached. RRF was significantly higher in CAPD patients $(3.69 \pm 2.37 \mathrm{~mL} / \mathrm{min})$ than in $\mathrm{HD}$ patients $(0.82 \pm 1.90 \mathrm{~mL} / \mathrm{min})$ $(p=0.0004)$. Conversely, the total weekly dialytic clearances of $\beta 2 \mathrm{M}$ and $\mathrm{p}$-cresol were significantly higher in HD patients $(17.2 \pm 0.63 \mathrm{~L} /$ week and $9.8 \pm 1.7 \mathrm{~L} /$ week, respectively) than in CAPD patients $(6.2 \pm 0.83 \mathrm{~L} /$ week and $5.9 \pm 0.69 \mathrm{~L} /$ week, respectively) $(\mathrm{p}<0.0001$ and $\mathrm{p}=0.0184$, respectively). No significant differences of dialytic clearances of UN, Cr or Ph were noted between CAPD and HD patients. Conclusion: The dialytic clearance of the MM $\beta 2 \mathrm{M}$ and the protein-bound solute $\mathrm{p}$-cresol across the peritoneal membrane 
is less effective than across a high-flux HD membrane. The lower serum levels in CAPD are most probably due to a better preservation of RRF.

3

\section{Effect of Substitution Flow Rate on Treatment Efficacy of Mid-Dilution Hemodiafiltration (HDF) with the Nephros Olpūr $^{\mathrm{TM}}$ MD 190 Hemodiafilter}

\author{
D.H. Krieter ${ }^{1,2}$, G. Collins ${ }^{3}$, J. Summerton ${ }^{3}$, \\ H.L. Moragues ${ }^{2}$, C. Formet ${ }^{2}$, L. Harrami², H.-D. Lemke ${ }^{4}$, \\ B. Canaud ${ }^{2}$ \\ ${ }^{1}$ Nephrology, University of Würzburg, Germany, \\ ${ }^{2}$ Nephrology, University of Montpellier, France, \\ ${ }^{3}$ Nephros, Inc., New York, USA, ${ }^{4}$ Membrana Research, \\ Obernburg, Germany
}

On-line mid-dilution HDF with the Nephros OLpūrTM MD 190 hemodiafilter represents a new concept, which enhances mass removal of middle molecules. Compared to post-dilution HDF performed near its operational limit ( $25 \%$ of blood flow), mid-dilution HDF allows the infusion of much higher substitution fluid volumes ( $\geq 50 \%$ of blood flow), thereby enhancing convective mass transfer without diluting solutes in blood to the extent found in pre-dilution HDF. In-vitro, a positive linear correlation between clearance and substitution rate $\left(\mathrm{Q}_{\mathrm{S}}\right)$ was observed for urea, cytochrome-C, and beta2 microglobulin $(\beta 2 \mathrm{~m})$. During simulated testing with bovine blood $\left(\mathrm{Q}_{\mathrm{B}}=400 \mathrm{ml} / \mathrm{min}, \mathrm{Q}_{\mathrm{D}}=800-\mathrm{Q}_{\mathrm{S}} \mathrm{ml} / \mathrm{min}\right), \beta 2 \mathrm{~m}$ clearance increased by $38 \mathrm{ml} / \mathrm{min}$ for each $100 \mathrm{ml} / \mathrm{min}$ increase in substitution rate. This net increase is similar to the difference in $\beta 2 \mathrm{~m}$ clearance observed in a clinical study $\left(10\right.$ patients, $\mathrm{Q}_{\mathrm{B}}=400 \mathrm{ml} / \mathrm{min}, \mathrm{Q}_{\mathrm{D}}=700-\mathrm{Q}_{\mathrm{S}} \mathrm{ml} /$ $\mathrm{min}$, where $100 \mathrm{ml} / \mathrm{min}$ higher substitution fluid rate in mid-dilution $\operatorname{HDF}\left(\mathrm{Q}_{\mathrm{S}}=200 \mathrm{ml} / \mathrm{min}\right)$ resulted in a $36.1 \mathrm{ml} / \mathrm{min}$ improvement in $\beta 2 \mathrm{~m}$ clearance vs post-dilution $\operatorname{HDF}\left(\mathrm{Q}_{\mathrm{s}}=100 \mathrm{ml} / \mathrm{min}\right)$ $(201.9 \pm 20.6$ vs. $165.8 \pm 26.6 \mathrm{ml} / \mathrm{min})$. In another clinical trial on 8 patients, we wanted to demonstrate the positive linear correlation between clearance and $\mathrm{Q}_{\mathrm{S}}$ in mid-dilution HDF. Maintaining the same $\mathrm{Q}_{\mathrm{B}}$ and $\mathrm{Q}_{\mathrm{D}}$ of 400 and $800-\mathrm{Q}_{\mathrm{S}} \mathrm{ml} / \mathrm{min}$, respectively, $\mathrm{Q}_{\mathrm{S}}$ was set at different flow rates of 100,150 , and $200 \mathrm{ml} / \mathrm{min}$. We were able to confirm our in vitro findings by measuring urea and $\beta 2 \mathrm{~m}$ clearances and additional treatment efficacy parameters, including solute reduction ratio and dialysate mass transfer, at each respective substitution rate.

\section{Beta2-Microglobulin ( $\beta 2 \mathrm{~m})$ Removal in Post-Dilution Hemodiafiltration (post-HDF) Is Influenced by Dialysis Membrane Permeability and Substitution Volume}

D.H. Krieter, S. Falkenhain, L. Chalabi, H.-D. Lemke, N. Sauer, A. Brand, C. Wanner, B. Canaud

Nephrology, University of Würzburg, Germany, Nephrology, University of Montpellier, France, Clinic Jacques Mirouze, Montpellier, France, Membrana Research, Obernburg, Germany

Background: High middle molecule removal is regarded as an important treatment goal in dialysis therapy in ESRD. In post-HDF, $\beta 2 \mathrm{~m}$ elimination is essentially determined by dialysis membrane permeability and substitution fluid flow rate (QS). Methods: In a randomized, prospective, cross-over study in 6 ESRD patients $(57.8 \pm 14.7$ years), on-line post-HDF was performed with two highflux dialysis membranes differing in permeability (DIAPES ${ }^{\circledR} \mathrm{HF} 800$, $1.9 \mathrm{~m}^{2}$, KUF $80 \mathrm{ml} / \mathrm{h} \times \mathrm{mmHg}$, and DIAPES ${ }^{\circledR}$ HF800XP, $2.0 \mathrm{~m}^{2}$, $\mathrm{KUF} 74 \mathrm{ml} / \mathrm{h} \times \mathrm{mmHg}$ ). Each patient was treated for $240 \pm 19 \mathrm{~min}$ with both filters at QS of 40,80, 100, and $120 \mathrm{ml} / \mathrm{min}$. Blood flow (QB) and dialysate flow (QD) were set constant at $400 \mathrm{ml} / \mathrm{min}$ and $700-\mathrm{QS} \mathrm{ml} / \mathrm{min}$, respectively. Blood samples were drawn for $\beta 2 \mathrm{~m}$ reduction ratios (RR), which were corrected for extracellular volume changes. $\beta 2 \mathrm{~m}$ mass transfer was determined in continuously collected dialysate. Results: $\beta 2 \mathrm{~m}$ RR for DIAPES ${ }^{\circledR}$ HF800 at QS 40, 80, 100, and $120 \mathrm{ml} / \mathrm{min}(78.5 \pm 4.5,81.5 \pm 3.2,82.3 \pm 5$, and $82.6 \pm 3.6 \%$, resp.) were throughout significantly higher $(\mathrm{p}<0.05)$ compared to DIAPES $^{\circledR}$ HF800XP $(69.3 \pm 4.4,76.6 \pm 4.9,76.3 \pm 3.3$, and $78.8 \pm$ $4.7 \%$, resp.). Larger $\beta 2 \mathrm{~m}$ amounts in dialysate were also measured with DIAPES ${ }^{\circledR}$ HF800 $(123 \pm 43,128 \pm 68,211 \pm 54$, and $229 \pm$ $74 \mathrm{mg}$, resp., versus $89 \pm 37,120 \pm 37,160 \pm 33$, and $183 \pm 36 \mathrm{mg}$, resp.), but reached statistically significant differences $(\mathrm{p}<0.05)$ only at QS 40 and $100 \mathrm{ml} / \mathrm{min}$. Conclusion: Compared to DIAPES ${ }^{\circledR}$ HF800XP, post-HDF with DIAPES ${ }^{\circledR}$ HF800 led to superior $\beta 2 \mathrm{~m}$ removal particularly at low QS. Increasing QS from 80 to $120 \mathrm{ml} / \mathrm{min}$ did not result in significantly higher $\beta 2 \mathrm{~m} R R$, but in enhanced dialysate mass transfer, a useful additional parameter in comparing treatment efficacy for $\beta 2 \mathrm{~m}$ of virtually non-adsorbing membranes. To achieve excellent $\beta 2 \mathrm{~m}$ removal in post-HDF, a high dialysis membrane permeability for $\beta 2 \mathrm{~m}$ can avoid critically high QS and transmembrane pressure-related problems. 


\section{5}

\section{Pre-Dilution On-Line Hemofiltration (HF) versus Ultrapure Low-Flux Hemodialysis (HD): A Randomized Prospective Study Evaluating the Effects on Cardiovascular and Nutritional Parameters, Quality of Life and the Uremic Toxicity Profile}

\section{Beerenhout, A. Luik, F. van der Sande, K. Leunissen, J. Kooman}

University hospital Maastricht, The Netherlands, vie curi Venlo, The Netherlands

Background: Accumulation of middle molecules (MM) may have a negative effect on the cardiovascular and nutritional state of dialysis patients, and influence uremic symptomatology. A greatly enhanced MM clearance can be achieved by the use of on-line HF. Methods: Aim of the study was to compare the cardiovascular and nutritional effects of low-flux HD (ultrapure dialysate; polyamide membranes) and pre-dilution on-line HF (1:1 blood/substitution ratio; target filtration volume $1.2 \times$ body weight). 43 patients were randomized. Results: The change in 48-hour systolic blood pressure did not differ between the HF $(135 \pm 18$ at baseline and $132 \pm$ $14 \mathrm{mmHg}$ after 12 months) and HD (129 \pm 23 versus $127 \pm$ $14 \mathrm{mmHg}$ ) group. Also left ventricular mass index did not change in the HF group $\left(130 \pm 34\right.$ at baseline versus $134 \pm 36 \mathrm{~g} / \mathrm{m}^{2}$ at 12 months) nor in the HD group $\left(132 \pm 30\right.$ versus $\left.131 \pm 30 \mathrm{~g} / \mathrm{m}^{2}\right)$, nor did pulse wave velocity (HF: $12 \pm 5$ versus $13 \pm 5 \mathrm{~m} / \mathrm{s}$; HD: $12 \pm 3$ versus $13 \pm 5 \mathrm{~m} / \mathrm{s}$ ). Lean body mass (DEXA) increased in HF patients $(44.8 \pm 8.9$ versus $46.2 \pm 9.6 \mathrm{~kg} ; \mathrm{p}<0.05)$, but not in the HD group $(49.4 \pm 9.2$ versus $50.6 \pm 8.8 \mathrm{~kg})$. Insulin like growth factor 1 levels decreased significantly in the HD group (220 \pm 94 versus $1,645 \pm 69 \mathrm{mg} / \mathrm{l} ; \mathrm{p}<0.05)$ but not in the HF group $(195 \pm 100$ versus $196 \pm 107 \mathrm{mg} / \mathrm{l})$; Quality of life (QOL; Laupacis questionnaire) improved with regard to physical symptoms in the HF group (4.2 \pm 1.2 versus $5.0 \pm 1.1 ; \mathrm{p}<0.01)$ but not in the HD group $(4.0 \pm 1.0$ versus $4.4 \pm 1.4)$. $\beta 2$ Microglobulin levels decreased in the HF group $(43.1 \pm 18.0$ versus $20.4 \pm 10.1 \mathrm{mg} / 1 ; \mathrm{p}<0.01)$, but not in the HD group $(39.2 \pm 18.7$ versus $42.8 \pm 17.1 \mathrm{mg} / \mathrm{l})$. Also complement D and homocystein decreased significantly in HF treated patients, whereas 1-assymetric dimethylarginine and leptin did not change. Conclusion: In this randomized study, on-line HF appeared to have significant beneficial effects on nutritional state compared to low-flux HD, whereas no differences in cardiovascular parameters were observed. However, the use of on-line HF resulted in marked changes in the uremic toxicity profile. Moreover, QOL improved with on-line HF.

\section{6}

\section{A Simple Method for Estimation of Internal Filtration/Backfiltration Flow Rate in High Flux Dialyzers}

\author{
M. Mineshima1, Y. Sato ${ }^{2}$, I. Ishimori', T. Akiba², \\ T. Sunohara ${ }^{3}$, T. Masuda ${ }^{3}$ \\ ${ }^{1}$ Kidney Center, Tokyo Women's Medical University, \\ ${ }^{2}$ Kidney Center, St. Marianna University, \\ ${ }^{3} \mathrm{R}$ \& D Laboratory, Nipro Corporation, Japan
}

In an effort to improve solute removal efficiency, several types of high flux dialyzers were developed and introduced for clinical applications. In these dialyzers, internal filtration/backfiltration (IF/BF) is induced by pressure drop of blood and dialysate flow in a countercurrent manner under less net filtration. Enhanced internal IF/BF increased convective transport of the solute in addition to diffusive transport. In previous published papers, we reported the effects of IF on solute removal efficiency of the dialyzer during an analytical and an experimental study and the measurement of the internal filtration flow rate $\left(\mathrm{Q}_{\mathrm{IF}}\right)$ by doppler ultrasonography. Average blood flow rate $\left(\mathrm{QB}_{\mathrm{av}}\right)$ at a cross-sectional plane, therefore, was measured by pulse doppler and the longitudinal $\mathrm{QB}_{\mathrm{av}}$ profile along the dialyzer was obtained using a probe slider that can move the probe in parallel along the dialyzer. This is an useful method for a bedside monitoring of the IF/BF flow rate of dialyzers because it is noninvasive to the patient and produces reliable data with higher reproducibility. However, this is a little bit complicated because an ultrasonic instrument and a slider in the water bath as special equipment are required. In this paper, a simple method, therefore, was introduced to estimate the IF/BF value based on the ultrafiltration coefficient (UF) and an apparent transmembrane pressure (TMP). During a comparative study, the estimated $\mathrm{Q}_{\mathrm{IF}}$ value by this method strongly correlated with the observed value by the Doppler ultrasonography.

\section{7}

Plasmadialysis: A Novel Dialytic Option?

M. Gonella, G. Pratesi, C. Baldin, G. Calabrese

Renal Unit, Laboratory of Clinical Pathology, General Hospital, Casale Monferrato, Italy

Background: On Haemodialysis, a high RBCs count impairs the dialytic efficiency, which could be improved by dialysing the plasma (Plasmadialysis, PLD). Methods: In order to test this hypothesis, the following technique was performed in a patient $(\mathrm{Hb} 11.4 \mathrm{~g} / \mathrm{dl})$ : the arterial blood line $(\mathrm{QB}=450 \mathrm{ml} / \mathrm{min})$ was connected with two parallel plasmafilters, and the highest allowed plasma flow (QPL) of $150 \mathrm{ml} /$ min was conveyed through a $1.7 \mathrm{~m}^{2}$ Polyamide haemodialyzer; at the outlet the plasma joined the blood exiting from the plasmafilters on the venous blood line. Small solute clearances obtained with 4 hours of PLD and high efficiency HD (QB $400 \mathrm{ml} / \mathrm{min}$, using a Polyamide $1.7 \mathrm{~m}^{2}$ haemodialyzer) were compared. Moreover, on both techniques, plasma small solute concentrations were measured at the haemodialyzer inlet and outlet at the start of the session. Results: Urea, creatinine and phosphate clearances ( $\mathrm{ml} / \mathrm{min}$ ) were lower on PLD than HD 
$(179,176,138$ vs $256,198,147$, respectively). However, at the haemodialyzer outlet the decrease of BUN (from 162 to $0 \mathrm{mg} / \mathrm{dl}$ ), $\mathrm{sCr}$ (from 8.5 to $0.02 \mathrm{mg} / \mathrm{dl}$ ) and sPi (from 4.7 to $0.12 \mathrm{mg} / \mathrm{dl}$ ) was almost $100 \%$ on PLD, whereas it was 80,67 and $65 \%$ respectively on HD. Conclusion: The limiting factor of this experimental technique was the low QPL (around 30\% of QB). The encouraging aspect was the complete removal of small solutes through the haemodialyzer. Therefore, an increase of QPL could improve PLD performance, even compared with the most efficient dialytic techniques. Of course, this technique would need an authomatic equipment in view of its clinical use in RDT.

\section{8}

\section{Long-Term Crossover Comparison of Ultrapure High-Flux Haemodialysis and Online Haemodiafiltration: A Prospective 4-Year Clinical Study}

\section{H. Schiffl, S.M. Lang}

$\mathrm{KfH}$ Nierenzentrum, München Laim und Department of Internal Medicine, University of Munich, Munich, Germany

Haemodiafiltration combines removal of solutes by diffusion and convection. Theoretically, it should represent the best available form of renal replacement therapy (RRT) but long-term clinical outcome data are not available. 76 haemodialysis patients treated with highflux dialysers and ultrapure dialysate were randomised either to online post-dilution haemodiafiltration or to ultrapure high-flux haemodialysis for 24 months. Thereafter, they crossed to the other form of RRT for another 24 months. The two study groups did not differ significantly in demographic data, renal characteristics or treatment parameters at recruitment. 61 patients completed the study and their data were included in the analysis. Online haemodiafiltration therapy resulted in a significant and sustained decrease in serum beta-2-microglobulin concentrations and in a higher $\mathrm{Kt} / \mathrm{V}$ urea compared to high-flux haemodialysis. However, enhanced solute removal did not cause differences in pre-dialysis small solutes values, residual renal function, haemodynamic or anaemia control, degree of hyperparathyroidism, or perception of quality of life. Given the small numbers of patients and the limited long-term follow up of our study, it was not possible to show a definitive clinical benefit from the use of haemodiafiltration which was associated with higher costs.

\section{9}

\section{Daily On Line Hemodiafiltration: A Pilot Experience in Children}

\section{Fischbach, V. Laugel, C. Dheu, P. Helms \\ Nephrology Dialysis Transplantation Children's Unit, Strasbourg, France}

Despite the major improvements in children dialysis care over the last two decades, the cardiovascular outcome stays at a high even unacceptable level of mortality risk factor. Therefore, we conducted a study with conversion to daily dialysis, without important reduction of each dialysis duration, allowing gentle ultrafiltration rate to reach dry weight. Five oligoanuric preadolescents, mean age $13.8 \pm 3.2$ years were converted from standard on line hemodiafiltration (SOL-HDF), 3 times $4 \mathrm{~h}$, to daily on line hemodiafiltration (D-OL-HDF), 6 times $3 \mathrm{~h}$, patients elected considering their uremic cardiomyopathy. The same dialysis parameters were used in D-OL-HDF for S-OL-HDF. All had travel time to the hospital less than $1 \mathrm{~h}, 3$ of them less than $30 \mathrm{~min}$. Increasing the number of sessions per week, has a positive significant impact on weekly dialysis dose: $\mathrm{TAC}_{\text {urea }}$ and $\mathrm{TAD}_{\text {urea }}$ decreased, and $\mathrm{nPCR}$ increased from $1.28 \pm 0.23 \mathrm{~g} / \mathrm{kg}$ to $1.43 \pm 0.24$ at 6 months, mean arterial BP reduced (from $95 \pm 15 \mathrm{mmHg}$ to $82 \pm 13$ at 6 months, to $87 \pm 9$ at 12 months), left ventricular hypertrophy decreased and function improved (FS; from $26.6 \pm 17 \%$ to $31 \pm 14 \%$ at 6 months, to $46.6 \pm 15 \%$ at 12 months), predialytic phosphatemia decreased (from $1.87 \pm 0.23 \mathrm{mml} / 1$ to $1.43 \pm 0.22$ at 6 months, to $1.28 \pm 0.29$ at 12 months), postdialytic recovery time disappeared, as was the fatigue perception. School attendance became regular even the half day before or after the dialysis session. In the only prepubertal child included, a catch up growth was noted conducting to a height score gain of 1.5 DS over a 24 months period. This D-OL-HDF strategy restored patient confidence and motivation. Nevertheless, long term acceptance of such a 'long and daily' dialysis schedule, may lead to abandon the technique if not included in a life project, the final goal being to restore clinical condition allowing registration on kidney transplantation waiting list.

\section{0 \\ Heparin-Free Dialysis in Pre-Dilution Hemodiafiltration Possible without Extra Flushing}

\author{
K. Wingren, M. Alquist \\ Park Dialys Clinic, Lund, Sweden
}

Aim: In clinical practise we have observed that predilution hemodiafiltration (preHDF) requires less heparin than standard hemodialysis (HD). We compared heparin-free preHDF, without periodic saline rinse, with heparin-free HD according to our standard procedure, which includes repeated rinsing of the dialyzer. Background: Ten patients on chronic HD were prescribed anticoagulant-free dialysis for medical reasons. They were dialyzed at consecutive sessions with the two modes studied in random order. 26 treatments were assessed ( 3 patients at 2 occasions). AK 200 ULTRA S monitors (Gambro) and Polyflux $17 \mathrm{~S}$ dialyzers were used. Treatment times were $240 \mathrm{~min}$, mean blood flows 395 and $386 \mathrm{ml} / \mathrm{min}$ in HD and HDF respectively. Infusion volume in HDF was on average $46.4 \mathrm{~L}$ giving a $1: 2$ dilution of blood. In both modes $1 \mathrm{~L}$ of isotonic saline was continuously infused in the venous drip chamber at $250 \mathrm{ml} / \mathrm{h}$. In HD the dialyzers were rinsed with $250-300 \mathrm{ml}$ isotonic saline every $30 \mathrm{~min}$ (total $2 \mathrm{~L}$ ). We looked at number of fulfilled 4-hour treatments, delivered dialysis dose (Kt/V-urea) and degree of clotting in the filter and venous drip chamber. White blood cells, trombocytes and CRP were measured before treatment to assess potential impact on clotting. Results: 25 treatments were completed as planned without complications. Mean $\mathrm{Kt} / \mathrm{V}$ was $1.37 / 1.35$ in HD/HDF. No significant diffference between the 
modes was found with respect to fulfilled treatments, dialysis dose, blood parameters or clotting in the drip chamber. Dialyzer clotting was significantly less in HDF. Conclusion: PreHDF using Polyflux filters and 1:2 dilution of blood allows anticoagulant-free treatment to be performed safely and effectively. The labour-intensive flushing of the filter, normally used in anticoagulant-free HD, is not required.

\section{1}

\section{Renal Failure after Cardiac Surgery}

\section{A. Griskevicius, J. Audzijoniene, M. Balciunas \\ Vilnius University Hospital, Santariskiu Clinics, Lithuania}

Background: Continuous venovenous hemofiltration (CVVHF) currently represents standard renal replacement therapy in criticall ill patients and produces better cardivascular stability during treatments patients after cardiac surgery. Methods: Patients treated with CVVHF for severe acute renal failure (ARF) after cardiac operation were identified using a prospective by collected intensive care unit database. The medical records of these patients were obtained and data were retrospectively recorded with focus on demographic features, surgical characteristics, hemodynamic, intensive care unit stay, survival to intensive care unit and hospital discharge. The technique of CVVHF consists of a double lumen catheter that is used pump blood through a module. Replacement fluid is administered prefilter at a dynamically adjusted rate chosen to achieve the desired fluid therapy goals. Anticoagulation with prefilter heparin of the circuit is carried out according to clinical judgment and circuit duration. The blood flow rate is kept at 100 to $200 \mathrm{ml} / \mathrm{min}$. Ultrafiltration pump controlled at 1-21/h. Results: We performed a retrospective analysis of 40 patients with ARF who underwent cardiac surgery and CVVHF during 2002 march and 2003 march. Their demographic and clinical characteristics are: age $63.5(20-84)$ years, gender M 26/F 14, coronary artery graft surgery 13 , left ventriculi and aneurisma of aorta 4 , valves 12 , valves and coronary artery graft surgery 6 , heart transplantation 2 , artificial left ventriculi 1 , trombectomia 1 , left ventriculi 1 , oliguria 26(65.0\%), peak urea (mmol/l) 30.8(12.6-58.2), peak creatinine (micromol/1) 394.7(218-600), mechanical ventilation 34(85.0\%), inotrope therapy $38(95.0 \%)$, intraaortic ballon pulsation $22(55.0 \%)$, Apache II 24.4(12-33), duration of CVVHF(hours) 70.6(3-277), the longest interval of CVVHF(hours)277, duration of CVVHF among 10 survived patients(hours) 78.4(14-136), hospital mortality among CVVHF patients 30(75.0\%). Conclusion: CVVHF treatment was associated with a better than predicted outcome. These results are encouraging and support our approach.
12

\section{Disinfection on Dialysis Monitors and Biofilm Impairment}

\author{
G. Cappelli', M. Ricardi', S. Perrone1, G. Ligabue1, \\ A. Di Felice1, M. Bondi', D. Fertolani3 \\ M. Rosati ${ }^{4}$, C. Tetta ${ }^{4}$ \\ ${ }^{1}$ Nephrology Dialysis and Renal Transplant Unit, \\ University Hospital of Modena, ${ }^{2}$ Department of \\ Biomedical Sciences, University of Modena, \\ ${ }^{3}$ SIS_TER SpA, ${ }^{4}$ Fresenius Medical care, \\ Palazzo Pignano (CR), Italy
}

Background: Dialysis monitor disinfection is an essential procedure to assure microbiological decontamination and absence of any biological stimulus to microinflammation to dialysis patient. Today this is even more important in relation to high efficiency and on-line procedures. Methods: We tested chemical and heat disinfection on a standard dialysis monitor (Fresenius $4008 \mathrm{H}$ ) contaminated with a Pseudomonas aeruginosa solution $\left(10^{\wedge} 9 \mathrm{CFU} / \mathrm{ml}\right)$ in the presence or absence of biofilm formation. Chemical disinfetion was performed using a peracetic acid derived product (Puristeril plus ${ }^{\circledR}$ ) associated, or not, to an hypochlorite based agent $\left(\right.$ Sporotal $\left.{ }^{\circledR}\right)$; heat disinfection was performed at $85^{\circ} \mathrm{C}$ with addition of an acid agent (Diasteril ${ }^{\circledR}$ ). Results: Results were evaluated immediately after and 72 hours post disinfection procedures for bacterial $(\mathrm{CFU} / \mathrm{ml})$ or endotoxin presence $(\mathrm{EU} / \mathrm{ml})$. In the absence of biofilm we confirmed certified results of more than 5 logarithmic reduction values (LRV) in CFU. In the presence of biofilm chemical disinfection offers an higher activity on Pseudomonas a. compared to heat disinfection (5.7 vs $2.7 \mathrm{LRV}$ ) and the presence of Sporotal ${ }^{\circledR}$ accounts for a 2 LRV effect. The same happens for endotoxins, as the combination Puristeril plus ${ }^{\circledR}$ and Sporota ${ }^{\circledR}$ offers the higher results $(\mathrm{LRV}=2.8)$, similar to heat disinfection only in the absence of biofilm ( $\mathrm{LRV}=2.2)$. In the presence of biofilm $85^{\circ} \mathrm{C}$ heat disinfection results in a low endotoxin removal both with or without Diasteril ${ }^{\circledR}(\mathrm{LRV}=0.9)$. Conclusion: Biofilm presence significantly affects disinfection procedures leading to a residual bacterial and endotoxin presence. Regrowing is a general phenomenon occurring inside the monitors when a low efficiency disinfection has been performed and could be demonstrated already at 72 hours post disinfection. Biofilm avoidance should be the goal. 
13

\section{A Systematic Review of Extracorporeal Renal Replacement Therapy (RRT) Techniques for End-Stage Renal Disease (ESRD)}

K.S. Rabindranath ${ }^{1}$, G.F.M. Strippoli², C. Daly ${ }^{2}$, P. Roderick ${ }^{3}$, S.A. Wallace ${ }^{4}$, A. MacLeod

${ }^{1}$ Medicine and Therapeutics, University of Aberdeen, Aberdeen, United Kingdom, ${ }^{2}$ Cochrane Renal Group, Center for Kidney Research, Children's Hospital at Westmead, Sydney, Australia, ${ }^{3}$ Health Care Research Unit, University of Southampton, Southampton, ${ }^{4}$ Health Services Research Unit, University of Aberdeen, Aberdeen, United Kingdom

Background: To evaluate the comparative efficacy of the different extracorporeal RRT methods; haemodialysis (HD), haemofiltration (HF), haemodiafiltration (HDF) and acetate free biofiltration (AFB) we performed a systematic review of randomised controlled trials (RCTs) comparing these RRT modalities. Methods: Clinical outcomes assessed: mortality, hypotension episodes, dialysis sessions associated with 'adverse symptoms' (headache, nausea and vomiting), hospital admissions, adequacy of dialysis, number of patients with amyloid related complications, $\beta_{2}$-microglobulin removal, and quality of life (QOL). We performed a comprehensive search, data concerning trial methodological quality and relevant clinical outcomes were extracted, and where appropriate entered for meta-analysis. Results: Of 1672 abstracts identified, 16 trials (354 patients) were included. Three HF vs HD; six, HDF vs HD; six, AFB vs HD; and one HDF vs AFB. The results were difficult to pool as the studies used variable outcomes and the overall quality of the studies was poor ' $\mathrm{HF}$, HDF, AFB and HD do not differ significantly from each other (six trials, 208 patients)'. Conclusion: Overall, HD, HDF, HF and AFB have not been shown to have significant advantage over one another with regard to mortality, dialysis related hypotension and manifestations of dialysis related amyloidosis. However the trials included in this review are small and are therefore inadequately powered to detect differences between effects of the relevant treatments.. An adequately powered pragmatic RCT comparing the above techniques accompanied by an economic evaluation is required.

\section{4}

\section{Hemodynamic and Renal Effects of Extracorporeal Ultrafiltration (UF) for Severe Heart Failure (HF)}

\author{
D. Weinstein' ${ }^{1}$, J. O'Neill', C. Gassensmith², W. Clark², \\ E. Paganini ${ }^{1}$, D. Taylor ${ }^{1}$ \\ ${ }^{1}$ Cleveland Clinic Foundation, Cleveland, $\mathrm{OH},{ }^{2} \mathrm{~N} x$ Stage \\ Medical, Inc., Lawrence, MA, USA
}

Background: HF is responsible for nearly one million hospitalizations and 300,000 deaths yearly in the US. The annual incidence of $\mathrm{HF}$, estimated at $>500,000$, is increasing in the US and cost of care for chronic HF may be $\cong 40$ billion USD. Therefore, alternative approaches are needed to improve patient outcomes and reduce costs. We studied the clinical effects of isolated UF with the NxStage System One in acutely decompensated chronic HF patients requiring ICU admission. Methods: Prospective, randomized study of UF vs usual and customary care for HF. At entry pulmonary capillary wedge pressure (PCWP) $>20 \mathrm{~mm} \mathrm{Hg}$ while the primary therapy endpoint was a sustained PCWP $<18 \mathrm{~mm} \mathrm{Hg}$. Patients randomized to UF underwent the procedure continuously for $\geq 48 \mathrm{~h}$ and could be treated with vasoactive compounds but not diuretics. Results: 5 patients (ejection fraction, $17.6 \pm 7.6 \%$; mean $\pm \mathrm{SD}$ ) underwent UF. On enrollment, mean hemodynamic parameters were: BP, $104 / 58 \mathrm{~mm} \mathrm{Hg}$; PCWP, $30 \mathrm{~mm} \mathrm{Hg}$; CVP, $21 \mathrm{~mm} \mathrm{Hg}$; PA pressure, $63 / 30 \mathrm{~mm} \mathrm{Hg}$; and $\mathrm{CI}, 2.3 \mathrm{~L} / \mathrm{min} / \mathrm{m}^{2}$. Mean baseline BUN and Scr were 47 and $1.4 \mathrm{mg} / \mathrm{dL}$, respectively, while the four-variable MDRD GFR estimate was $64.4 \mathrm{~mL} /$ $\min / 1.73 \mathrm{~m}^{2}$. Target hemodynamic parameters were achieved, mean $20.8 \pm 8.7 \mathrm{~h}$ with mean net negative fluid balance of $4020 \pm 1762 \mathrm{~mL}$ (hourly mean, $195 \pm 40 \mathrm{~mL}$ ). During the intervention and hospital follow-up periods, CI, BP, BUN, and Scr did not change significantly from baseline. At hospital discharge, mean BUN and Scr were $55 \pm$ 41 and $1.4 \pm 0.6 \mathrm{mg} / \mathrm{dL}$, respectively. Conclusion: Continuous UF allowed for rapid achievement of hemodynamic targets in acutely decompensated chronic HF with preservation of renal function. These preliminary data will be supplemented with ongoing enrollment in the trial.

\section{Haemodialysis}

15

\section{Soft Tissue Calcifications and Their Relation to PTH in Patients on Hemodialysis Treatment (HDT)}

\author{
D. Yonova ${ }^{1}$, M. Georgiev', P. Dukova ${ }^{2}$, S. Antonov ${ }^{1}$ \\ ${ }^{1}$ Dialysis Clinic, ${ }^{2}$ Centre for Medical Laboratory, \\ Medical University Hospital 'Alexandrovska', Sofia, \\ Bulgaria
}

The Aim of the Study: To evaluate the dispersion of vascular and periarticular soft tissue calcifications of a random group of HDT patients and their relation to PTH and some other biochemical markers. Material and Methods: 4 middle-range arteries a.a. carotis communis sinistra et dextra and a.a. femoralis sinistra et dextra were investigated by echography; 4 typical for calcium deposits periarticular regions of the body were checked by X-ray and visible skin calcifications were registered in 37 patients (on HDT more than 3 months) for evaluation of calcification rate, comparing them with some biochemical parameters: $\mathrm{PTH}, \mathrm{AP}, \mathrm{Ca}, \mathrm{Ca}^{++}, \mathrm{P}$ and C-reactive protein (CRP). Results: The study found a high percentage of vascular calcifications (VC) $-96 \%$, and a low percentage of periarticular and skin calcifications $-3.2 \%$. A significant correlations were found between PTH/AP $(r=0.7, p<0.001)$, PTH/VC $(r=0.51, p<0.001)$, $\mathrm{PTH} / \mathrm{Ca}^{++}(\mathrm{r}=0.40, \mathrm{p}<0.01)$ and PTH/CRP $(\mathrm{r}=0.39, \mathrm{p}<0.01)$ 
as well as between CRP/VC $(\mathrm{r}=35)$. Conclusion: The study suggests an association of II HPT and existing inflamatory status with vascular calcifications, but no relation of both factors to periarticular and scin calcium deposits.

\section{6}

\section{Valve Calcifications, Myocardial Function and Some Risk Factors in Dialysis Patients}

\author{
M. Georgiev, D. Yonova, S. Antonov, Z. Kirijakov \\ Dialysis Clinic, Medical University Hospital, \\ 'Alexandrovska', Sofia, Bulgaria
}

The Aim of the Study: To find some relations between cardiac valve calcifications and myocardial function in patients on hemodialysis treatment and to assess calcification risk factors. Methods: Conventional M-mode and B-mode echocardiography (Echo) and Pulsedoppler were made, accounting myocardial function and aorta valve calcifications (Ca-Ao), mitral valve calcifications ( $\mathrm{Ca}-\mathrm{M})$ and total valve calcifications score $(\mathrm{Ca}-\mathrm{Ao}+\mathrm{M})$ of 20 patient $(21$ males and 19 females), mean age $56 \pm 13$ years on haemodialysis treatment (HDT), mean duration $7.27 \pm 4.5$ years and 10 patients on CAPD. Arterial blood presure (ABP) and pulse rate were recorded. Serum levels of $\mathrm{Ca}^{++}, \mathrm{P}, \mathrm{AP}, \mathrm{PTH}, \mathrm{C}$-reactive protein (CRP) and Fetuin A were compared to myocardial function (ejection fraction-EF; endsystolic stress - ESS; VpE/VpA), muscle mass index (MMI), and valve calcifications rate. Results: Significant correlations were found as follows: $\mathrm{Ca}^{++} /$Cardiac Ca $\mathrm{r}=0.46, \mathrm{p}<0.01 ; \mathrm{PTH} /$ Cardiac $\mathrm{Ca} \mathrm{r}=0.43$, $\mathrm{p}<0.01 ; \mathrm{EF} / \mathrm{ESS} \mathrm{r}=0.81, \mathrm{p}<0.01 ; \mathrm{EF} /$ Cardiac $\mathrm{Ca} \mathrm{r}=-0.38$, $\mathrm{p}<0.05 ; \mathrm{CRP} / \mathrm{EF} \mathrm{r}=-0.4, \mathrm{p}<0.01 ; \mathrm{MMI} / \mathrm{MAP} \mathrm{r}=0.52, \mathrm{p}<0.01$; $\mathrm{VpE} / \mathrm{VpA}$ : Cardiac Ca $\mathrm{r}=-0.38, \mathrm{p}<0.05 ;$ Age/Cardiac $\mathrm{Ca} \mathrm{r}=0.4$, $\mathrm{p}<0.01$; Dur.HD/Cardiac Ca $\mathrm{r}=0.28, \mathrm{p}<0.05 ; \mathrm{PTH} / \mathrm{EF} \mathrm{r}=-0.22$, n.s. FetuinA/Cardiac $\mathrm{Ca} \mathrm{r}=-0.76, \mathrm{p}<0.001$; FetuinA/CRP $\mathrm{r}=$ -0.41 Fetuin A/PTH $r=-0.34$. Discussion and Conclusions: The results prove the negative influence of increased myocardial burden (ESS, ABP) on the left ventricular function and on MMI. Close relations of disturbed mineral metabolism, PTH, inflamatory status (CRP), Fetuin A, age and duration of HD with the rate of valve calcifications show that cardiac calcium deposits have multifactorial origin. The study also suggests that valve calcifications lead to damage of valve structure and left ventricular dysfunction in HD patients.

\section{7 \\ Clinical Practice Guidelines in Calcium and Phosphate Metabolism - Are They Achievable?}

\author{
S.P. Curran, J.A.B. Keogh, G.J. Mellotte
}

Department of Renal Medicine, Adelaide \& Meath Hospital, Tallaght, Dublin, Ireland

Background: Abnormalities in calcium and phosphate metabolism are associated with increased morbidity and mortality. New clinical practice guidelines regarding phosphorus $\left(\mathrm{PO}_{4}\right)$, calcium $(\mathrm{Ca})$ and parathyroid hormone (PTH) levels have been set by K/DOQI. These differ from the UK \& Ireland Renal Association (RA) guidelines. Are they achievable? Methods: Clinical records of 144 patients (80 haemodialysis and 64 peritoneal dialysis) receiving renal replacement therapy were retrospectively audited. Results: The mean values achieved were; $\mathrm{P}_{4}=1.74 \pm 0.57 \mathrm{mmol} / \mathrm{L}: \mathrm{Ca}=2.50 \pm 0.26 \mathrm{mmol} / \mathrm{L}$ : $\mathrm{PTH}=361 \pm 345 \mathrm{pg} / \mathrm{ml}$. The percentage of patients who met targets were; $\mathrm{P}_{4}=\mathrm{K} / \mathrm{DOQI}-42 \%$, RA-56\%: Ca $=\mathrm{K} / \mathrm{DOQI}-22 \%$, RA-67\%: $\mathrm{PTH}=\mathrm{K} / \mathrm{DOQI}-26 \%$, RA-52\%. The percentage of patients above the upper acceptable limit were; $\mathrm{P}_{4}=\mathrm{K} / \mathrm{DOQI}-42 \%$, RA-44\%: $\mathrm{Ca}=\mathrm{K} / \mathrm{DOQI}-72 \%$, RA-24\%: PTH $=\mathrm{K} / \mathrm{DOQI}-43 \%$, RA-48\%. Conclusion: There was a considerable difference between the recommendations. This shows that with current clinical practice it is more difficult to achieve the new targets. More intensive efforts are required to meet these guidelines.

\section{8 \\ Renal Osteodystrophy in the Non-Calcium Phosphate Binder and Calcium Receptor Agonist Era}

\author{
G. Coen \\ La Sapienza University, Rome, Italy
}

Renal osteodystrophy (ROD) is an important complication of CKD, encompassing different histologic subtypes, basically divided in low and high turnover bone disease. The prevalence of the pathologic classes differs in the published reports and has been changing in the last decades. Aluminium related osteomalacia, with special regards to some geographic areas, and a high percentage of adynamic bone disease (ABD), both in non-dialytic CKD and in HD, have been reported as a frequent finding. This shift from high turnover bone disease to predominance of low-turnover subtypes has been attributed to aluminum intoxication, to large intakes of calcium containg phosphate binders and to vitamin D metabolites for suppression of hyperparathyroidism. The introduction of new non calcium-phosphate binders, while lessening the risk of vascular calcifications, will probably reduce the calcium burden, resulting in a lower suppression of parathyroids and lower occurrence of ABD. A lower prevalence of ABD should also result in a better prevention of extraskeletal calcifications. In addition, the use of lantahanum containing binders should result in optimal phosphate chelation, without bone damage, at least based on recent reports of a 2-years long observation in man. So far no data have been published concerning the effect of calcimimetics on bone. In general, suppression of PTH, mainly through a drug unable to increase CaxP serum levels and apparently not endangering other vital organs, will be of evident advantage in the treatment of renal bone disease and hyperparathyroidism. Vitamin D, in addition to calcimimetics, in case of insufficient PTH control, will probably be better tolerated than in case of its use alone. Other risk cofactors of bone damage in CKD should also be considered, like vitamin D deficiency, malnutrition, low BMI and low gonadal hormones, with special regard to postmenopausal women. Some of these risk factors can be detected and addressed. 
19

\section{The Effect of Percutaneous Ethanol Injection Therapy for Parathyroid Gland on Advanced Secondary Hyperparathyroidism in Hemodialysis Patients}

\section{K. Tsuchida, T. Nakatani, R. Yoshimura, M. Matsuyama, T. Naganuma, K. Sugimura, Y. Takemoto \\ Department of Urology and Division of Artificial Kidney, Osaka City University Graduate School of Medicine, \\ Osaka, Japan}

Background: Parathyroid percutaneous ethanol injection therapy (p-PEIT) has been aggressively performed for secondary hyperparathyroidism (2-HPT). However, some patients could be treated with p-PEIT and internal treatment alone while others resulted in parathyroidectomy (PTX) and autograft from the forearm. In this regard, we investigated the effect of p-PEIT on 2-HPT. Methods: p-PEIT was performed total 101 times in the 35 hemodialysis patients against the complication of 2-HPT to investigate the therapeutic effect and adverse reactions after each p-PEIT. In addition, the patients were classified by the outcome into a group in which the treatment was possible with p-PEIT alone (p-PEIT group) and another in which total parathyroidectomy (PTX group) became necessary to investigate the factors contributing to the difference in outcome. Results: p-PEIT significantly decreased parathyroid hormone (PTH) but difficulty of puncture and transient hoarse voice occurred along with an increase in the frequency of treatment. Compared with the p-PEIT group, the PTX group demonstrated a significantly more swollen parathyroid glands. In addition, the maximum effect after p-PEIT was lower and an increase in intact PTH occurred as a rebound in this group. Conclusion: Based on the above, PTX should be considered in the initial stage in the case of advanced 2-HPT observed in hemodialysis patients because it is difficult to treat many of these patients with p-PEIT alone.

\section{0}

\section{Relationship Between Interleukin-6 Production and Plasma Levels of PTH in Patients on Chronic Hemodialysis}

I. Griveas, G. Visvardis, A. Fleva, D. Papadopoulou,

A. Giannakou, E. Mitsopoulos, P. Kyriklidou, E. Manou,

E. Ginikopoulou, D. Meimaridou, A. Pavlitou,

G. Sakellariou

Nephrology Department, Papageorgiou General

Hospital, Thessaloniki, Greece, Immunology

Department, Papageorgiou General Hospital,

Thessaloniki, Greece

Background: It is well accepted that the bone resortive effects of PTH occur, in a part by inducing osteoblasts to secrete cytokines that stimulate both differentiation and activation of osteoclasts. In order to investigate cytokine productions in patients undergoing hemodialysis (HD), we studied the production of IL-6 and its possible relationship with plasma PTH levels. Methods: We examined the serum levels of
IL-6 and plasma intact PTH in 79 HD patients (45 male, mean age: $63.43 \pm 10.04$ years $\mathrm{M} \pm \mathrm{SD}$ ) of whom 20 were on therapy with vitamin-D compounds. CRP levels, albumin and pre-albumin levels were also evaluated. Results: In patients on $\mathrm{HD}$, plasma levels of IL6 were $13.04 \pm 24.31 \mathrm{pg} / \mathrm{ml}(\mathrm{M} \pm \mathrm{SD})$ (normal values: $<3.13 \mathrm{pg} / \mathrm{ml}$ ). $85 \%$ of the study population had IL-6 levels over the upper normal limit. PTH values ranged from $4-2,500 \mathrm{pg} / \mathrm{ml}$ in our study population. There was no significantly correlation between intact PTH levels and levels of IL-6, CRP albumin and prealbumin. Similarly vitamin D didn't seem to influence IL-6 levels. On the contrary, IL-6 was positively correlated with CRP levels $(r=0.578)$ and negatively correlated with albumin $(\mathrm{r}=-0.333)$ and prealbumin $(\mathrm{r}=-0.408)$. Conclusion: Our hemodialysis patients seemed to have an enchanced release of IL-6. Patients with poor low albumin and prealbumin showed higher IL-6 production in immune response. Our data indicated that although abnormalities in the IL-6 system have the potential to affect bone turnover and to modulate the effects of PTH, neither the levels of PTH nor vitamin D therapy altered this aspect of IL-6 production.

\section{1}

\section{The Effect of Intermittent Compression of Upper Arm Veins on Forearm Vessels in Patients with End-Stage Renal Disease}

\author{
R.R. Rus, R. Ponikvar, R.B. Kenda, J.B. Ponikvar
}

Department of Pediatric Nephrology, University Medical Center, Department of Nephrology, University Medical Center, Turkey

Background: Native arteriovenous fistula is the best vascular access for chronic hemodialysis. Primary and long-term success depends, in part, on the state of arteries and veins at the time of the operation. The aim of our study was to investigate the effects of intermittent compression of upper arm veins on forearm vessels in patients with terminal renal disease. Methods: The study group comprised sixteen chronic hemodialysis patients who performed daily intermittent compression of the upper arm without vascular access by elastic band (Eschmarch). Ten chronic hemodialysis patients were included in the control group which performed no specific activity. Forearm measurements were obtained at the beginning of the study and four and eight weeks later during the course of intermittent compression of the upper arm veins. The forearm circumference and maximal handgrip strength were measured. The artery parameters, including endothelium-dependent vasodilatation and forearm vein parameters, were obtained by ultrasonography measurements. Results: The forearm circumference, maximal handgrip strength and artery parameters, including endothelium-dependent vasodilatation, remained unchanged. The basal venous diameters ( $2.29 \mathrm{~mm} \pm 0.19$ at the beginning, $2.46 \mathrm{~mm} \pm 0.19$ after four weeks and $2.53 \mathrm{~mm} \pm 0.18$ after eight weeks) were significantly increased in the study group. The distensibility of veins was preserved in the study group. There were no significant changes in the control group. Conclusion: Our study demonstrated that daily intermittent compression of the upper arm veins increases the forearm vein diameter and preserves the distensibility of veins in patients with end-stage renal failure. 


\section{2}

\section{High Output Heart Failure in Patients with Upper Arm A-V Fistulae: Diagnosis and Treatment}

\author{
R. Amerling, I. Malostovker, A. Dubrow, H. Rosero, \\ S. Haveson \\ Division of Nephrology and Hypertension, \\ Division of Cardiology, Division of Vascular \\ Surgery, Beth Israel Medical Center, \\ New York, NY, USA
}

Arteriovenous fistula (AVF) is the preferred blood access for hemodialysis due to its longevity and resistance to infection. Little attention is given to the long term hemodynamic consequences of large left-to-right shunts, particularly in patients with brachial artery fistulae. We describe 9 patients ( 8 on dialysis, 1 post-transplant), aged 25-73, who developed clinical heart failure, felt to be primarily due to large, upper arm AVFs. 3/9 had access flows in excess of 2 liters/min, assessed by blood temperature monitoring. 6/9 had cardiac output measured by right heart catheterization, before and after shunt compression. One also underwent left heart catheterization with ventriculography. 3/9 had surgical reduction of the fistula, either by banding or by serial interposition of small caliber GoreTex graft. In 2/9 the shunt was ligated. One patient had heart failure in association with 2 large, upper arm AVFs, one of which was ligated. After years of improved cardiac symptoms, heart failure recurred in association with marked hypertrophy of his remaining AVF. Resting cardiac output in this patient was in excess of 11 liters/min. 2/9 experienced acute onset of heart failure within 1-3 days of angioplasty of a venous stenosis. One of these, with very poor baseline cardiac function, expired. Surgical revision or ligation was accompanied by clinical improvement in the 5 patients so treated. One of these expired of a stroke after two months of cardiac improvement. High output heart failure is under-diagnosed in dialysis patients. Patients with large upper arm shunts are particularly at risk. Access flow should be assessed regularly and those with outputs $>1.5$ liters $/ \mathrm{min}$ should be monitored closely for development of heart failure. Surgical correction is beneficial and indicated in symptomatic patients.

23

\section{Arteriovenous Fistulas for Hemodialysis; Patency Rates and Complications: A Prospective Study}

\author{
Ö. Karabay', U. Yetkin², H. Öno/ ${ }^{3}$ \\ ${ }^{1}$ Dokuz Eylul University, Department of \\ Cardiovascular Surgery, ${ }^{2}$ Ataturk Education and \\ Research Hospital, Department of Cardiovascular \\ Surgery, ${ }^{3}$ Alsancak State Hospital, Department of \\ Cardiovascular Surgery, Izmir, Turkey
}

Background: The surgical technique we use, our patency rates, complications, experiences and results on arteriovenous fistulas for vascular access of hemodialysis patients are presented. Material and Method: Between January 1997 and December 2002 arteriovenous fistula operations in 486 chronic renal failure cases for vascular access are investigated prospectively. Non-dominant arm is chosen for the operation. In 94 cases a reoperation was applied due to thrombosis and failure to mature. In 24 cases a third operation was performed at the brachial level due to nonfunctioning former fistulas. Results: Of the 486 cases, 293 cases were male (60\%) and 193 cases were female (40\%). The mean age was 47.13 . Following the first operation, in 392 cases, the patency of fistula was obtained. In 94 cases, whose fistulas did not function initially, 40 were reoperated (42\%) at the brachial artery level, whereas the remaining 54 (58\%) underwent the Brescia-Cimino type fistula operation on contralateral arm. 21 cases needed a third operation at the brachial artery level using autogenous artery and vein due to failure of the second fistula. In 486 cases, 601 operations were performed totally without using a synthetic graft material and additional surgical intervention at the femoral artery level, reaching functioning fistulas finally. Results: While performing vascular access surgery, functioning of anastomosis, avoiding from complications and a long-term use of fistula were aimed. The Brescia-Cimino type distal arteriovenous fistula (AVF) should be performed as the first choice for vascular access.

\section{4 \\ Surgical Method to Giant Aneurysm in Arteriovenous Fistula (AVF) for Hemodialysis (HD)

\begin{abstract}
Ö. Karabay ${ }^{1}$, U. Yetkin², E. Silistreli ${ }^{1}$, H. Önol ${ }^{3}$, Ü. Açike/ ${ }^{1}$
${ }^{1}$ Dokuz Eylul University, Department of Cardiovascular Surgery, ${ }^{2}$ Ataturk Education and Research Hospital, Department of Cardiovascular Surgery, ${ }^{3}$ Alsancak State Hospital, Department of Cardiovascular Surgery, Izmir, Turkey
\end{abstract}

Background: $\mathrm{AVF}$ is the preferred access for $\mathrm{HD}$, hence increase the quality of life in the patients having chronic renal insufficiency. The most frequently seen complication in the late period is aneurysm formation. Material and Methods: We studied 18 patients who were operated on between the dates of June 1997 and June 2003, for giant aneurysms $>8 \mathrm{~cm}$, which had been developed on the AVF. Eleven patients $(61.1 \%)$ were male, mean age $43.1 \mathrm{y}$. Except for the one patient which were operated for spontaneous aneurysm rupture in the emergency conditions, color duplex ultrasonographic examination of the upper extremity were performed in all patients in the preoperative period, and the surgical method included aneurysm resection, afterwards rebuilding the arterial continuity. Results: Any of the complications such as infection, ischemic extremity loss, neurologic sequela and mortaity did not take place. Color duplex ultrasonographic examinations that were made in the late period of 6 months were all normal. The mean follow-up period of the patients after the aneurysm resection was 29.1 months (7-50 months). Any additional vascular complication could not be observed during the follow-up. Conclusion: Aneurysm formation, which is a complication of arteriovenous fistula, is a pathologic process seen in the late period due to the usage of the fistula, and early surgical intervention is the recommended choice of therapy because of the risk of spontaneous rupture. 


\section{5 \\ The Effect of Adventitial Dissection in Brachiobasilic Arteriovenous Fistulas (AVF) Opened in Children as Vascular Access for Hemodialysis (HD) on Patency and Maturation of Fistula}

\author{
Ö. Karabay', M. Bak², E. Silistreli', S. Calkavur ${ }^{2}$, I. Yurekli', \\ H. Agin'2, I. Algin', Ü. Açikel' \\ ${ }^{1}$ Dokuz Eylul University Hospital, Department of \\ Cardiovascular Surgery, ${ }^{2}$ Behcet Uz Children Hospital, \\ Division of Nephrology, Izmir, Turkey
}

Background: In this prospective study of 30 pediatric cases, $7 \mathrm{M}(23.3 \%)$ mean age $12.3 \pm 2.9$ (ranging between 7 and 17), and weight was $25.5 \pm 7.9 \mathrm{~kg}$ (range 16-44) undergoing HD, the role of adventitial dissection - performed to brachiobasilic AVF at antecubital area - on patency rate, maturation and early initiation of dialysis is investigated. Material and Method: Only brachiobasilic AVF were included; Group I $(\mathrm{n}=15)$ adventitial dissection, and Group II $(\mathrm{n}=15)$, no adventitial dissection. Results: In 29 cases thrill was present and HD has been initiated after the 4th week when the AVF had matured. The mean duration of follow-up was $12.53 \pm 8.98$ months in Group I, and $11.85 \pm 7.55$ in Group II ( $p=0.880)$. In Group I, 1 case developed AVF infection in the 2nd month, one developed lymphatic drainage, whereas in Group II, 1 case developed early thrombosis, 1 case hematoma, 1 case transient ischemia due to arterial spasm. One case in each group developed minimal edema in forearm treated conservatively. Primary patency rates were $93.3 \%$ in both groups whereas secondary patency rate was $100 \%$ in Group I. Conclusion: Adventitial dissection performed to vein during AVF formation does not improve AVF maturation, early initiation of dialysis or patency. Among pediatric HD, in cases of inadequate forearm veins, brachial AVF performed with meticulous surgical technique is the preferred option, with minimal complication and high patency rates.

\section{6}

\section{Vascular Access (VA) Survival as an Achilles' Heel: An Ancient Unsolved Problem?}

\section{Burdese, F. Bermond, V. Consiglio, F. Fop, E. Mezza, \\ D. Bergamo, G. Mangiarotti, A. Pacitti, S. Maffei, \\ G. Martina, G.P. Segoloni, G.B. Piccoli \\ Chair of Nephrology of the University of Torino, \\ Torino, Italy}

Background: VA was defined as the Achilles' heel of haemodialysis (HD). Patients' features and dialysis modalities, settings and schedules were considered as factors potentially affecting VA survival. Operator dependent procedures are an important confounding factor, making comparisons difficult. Aim of the Study: was to analyse VA survival, according to the main patient and treatment features, in a dialysis network characterised by tailored treatment schedules, with wide use of daily HD (DHD) and development of a home self-care dialysis program. Methods: All patients treated in an out-of-hospital
HD network were analysed in the period November 1988-June 2004. VA survival was related to age, gender, sex, comorbidity, previous vascular events, schedule (5-6/week versus 1-4/week), setting of treatment, dialysis follow-up, type of VA (native-prosthetic, first-subsequent) and setting of VA creation. The following end-points were analysed alone or in combination by univariate and multivariate models: VA failure, surgical treatment, angioplasty, and declotting with urokinase. Results: 88 patients, $\mathrm{M} / \mathrm{F}=61 / 27$ (43 at home or in training, 45 on Limited-Care dialysis), median age 49 years. At least one comorbid factor was present in 70 patients. The overall follow-up was 3,045 patient-months. In this period, 69 adverse events occurred (33 failures). There were no significant differences in gross incidence comparing Home vs Limited-Care dialysis (2.4/100 and 2.1/100 patient-months respectively) or DHD vs non-DHD schedules (2.1/100 and 2.3/100 patient-months respectively). Significant factors affecting survival were sex (male protective in some uni- and multivariate models) and VA creation setting (lower risk of VA complications in our Center). Conclusion: VA is a problem on HD, possibly more dependent on the operator than on the schedule, the setting or the single patient.

\section{7}

The Clinical Utility of Real-Time Ultrasound Three-Dimensional (3-D) Imaging System with Vessel Volume Mode in Primary Dialysis Access

\author{
T. Tokumoto ${ }^{1}$, N. Kimata ${ }^{1}$, K. Nagai ${ }^{1}$, E. Watanabe', \\ Y. Yamashita', T. Mochizuki², K. Tanabe', T. Akiba1, \\ H. Toma \\ ${ }^{1}$ Kidney Center, Tokyo Women's Medical University, \\ ${ }^{2}$ Research Laboratory, Aloka co., Ltd, Japan
}

Introduction: Some patient groups with end-stage renal disease (ESRD), have reduced success rates with radial-cephalic fistulas (AVF). Objectives: We evaluated the progression of vessels by the real-time ultrasound 3D imaging system with vessel volume mode (Vol-mode) in primary AVF. Materials and Methods: 23 ESRD were studied, mean age 59.7 y, $12 \mathrm{M}, 21.7 \%$ diabetes mellitus (DM). We used an ultrasound system, SSD-1000 equipped Vol-mode function and 3-D scanner with 7.5 MHz linear probe (ALOKA Co., Ltd., Tokyo, Japan). At the time of the scanning, 3-D images of the vessels are displayed with volume rendering technology in real-time. When the 3-D image of vessel was obtained, we measured the diameter of vessels in $3 \mathrm{~cm}$ interval from AVF anastomosis. The diameter of vessels with Vol-mode was compared between pre-operation and postoperation after 2 weeks. Results: The diameter of vessels increased (mean 3.9 to $7.0 \mathrm{~cm} \mathrm{M}$ vs mean 3.1 to $4.9 \mathrm{~cm} \mathrm{~F}$ ). The progression of vessels in $\mathrm{M}$ (1.8 times) was significantly greater vs $\mathrm{F}$ (1.6 times). The diameter of vessels in DM was mean 3.6 to $5.7 \mathrm{~cm}$ vs mean 3.5 to $6.1 \mathrm{~cm}$ in non DM group. The progression rate of vessels in DM group (1.6 times) was poorer than that in non DM group (1.8 times). The progression rate of vessels in more than 65 years of age was poorer than that in others. When the diameter of vessel was equal to or less than $2.5 \mathrm{~mm}$ before operation of AVF, both the progression rate of vessels and the blood flow in dialysis access were poor in 3 (all) cases. Conclusions: The real-time ultrasound 3D imaging system with Vol-mode seemed to be effective for assessing dialysis access. 


\section{8 \\ Nondestructive Evaluation of Blood and Dialysate Flows in Dialyzers Using X-Ray Computed Tomography}

Y. Sakai, M. Kubota, H. Takahashi, T. Kurachi, T. Koike, N. Kumano

Toray Industries, Inc., International University of Health and Welfare, Tokyo, Japan

Background: It is very important to observe the state of concentration or flow pattern of the blood and dialysate in dialyzers to evaluate their function and to obtain the most appropriate design. We established a visualization method for the blood and the dialysate flow pattern in dialyzers with X-ray computed tomography (CT) and investigated so-called internal filtration phenomenon. Methods: As a contrast medium, BaSO4 (BaritopR, Kaigen, Osaka) was used those nominal particle radius was 0.8 microns. Two percent of BaSO4 was added to bovine blood (Ht:30\%, TP:6.5 g/dL) or dialysate (saline) which were perfused through dialyzers to observe stable situation, and dialysate with $20 \%$ BaSO4 was injected in pulse manner to observe the distribution of dialysate flow. CT-scanner (XforceR, Toshiba, Tokyo ) was used in dynamic scan or helical scan mode. BS-1.6UL (previous model) and TS-1.6UL (new model) were used as samples (ToraysulfoneR, Toray, Tokyo). Both models are equipped with polysulfone hollow fibers. The latter one has an 'All Baffle Structure' in which helical slits are arranged on the baffle surrounding all portions at dialysate inlet and outlet to realize uniform flow. Their internal filtration rates, dialysate flow patterns were analysed. Results: 1) The changes of the ultrafiltration rate and blood pressure drop were negligible even when BaSO4 was added to bovine blood, which denotes that this method will show the flow pattern without severe artifact. 2) Relationship between the concentration of $\mathrm{BaSO} 4$ and $\mathrm{CT}$ number was expressed by a linear regression, which suggests the possibility that this method is used for quantitative analysis. 3) CT number was increased massively at just downstream of blood inlet, and the peak elevated with dialysate perfusion after the following conditions were set stable; blood flow rate: $200 \mathrm{ml} / \mathrm{min}$, dialysate flow rate: $500 \mathrm{ml} / \mathrm{min}$. It was understood that the $\mathrm{CT}$ number may show not only the internal filtration phenomenon but also the accumulation of $\mathrm{BaSO} 4$ on the membrane surface similarly to the protein polarization. 4) The internal filtration rate was calculated as $33 \mathrm{ml} / \mathrm{min}$ for TS-1.6UL by combining with the estimation of backfiltration region and the dependency of CT number on ultrafiltration rate. The region where $\mathrm{BaSO} 4$ was trapped into the peculiar porous structure of outer membrane surface after BaSO4 added saline was perfused in dialysate side, was understood as backfiltration region. 5) The dialysate flows more uniformly with TS-1.6UL than BS-1.6UL, when the flow pattern was pursued after pulse injection of BaSO4. Conclusion: This method can be utilized not only qualitatively but also quantitatively in observation of real state of blood and dialysate flows and in designing of new dialyzer. The flow pattern in dialysate became more uniform in the new model comparing with the previous one. Further studies are needed for this technique to be applied in estimation of internal filtration rate for various dialyzers in common.

22nd Annual Meeting of the International

Society of Blood Purification (ISBP)

\section{9}

\section{Renal Failure in Yemen}

\section{Al-Rohani}

Nephrology Hospital at Hajah Yemen, Hudaidah, Yemen

Renal failure remains a serious cause of mortality in Yemen. Our region has 1.25 million population and our hospital is the central hospital, which has nephrology department and dialysis in region. Between January 1998 and December 2002 we admitted 547 patients including children with acute and chronic renal failure. Chronic renal failure (CRF) was found in 400 patients with incidence $64 / \mathrm{million} /$ year and prevalence $320 /$ million. Acute renal failure (ARF) was in 147 with incidence $23.5 /$ million/year and prevalence 117.5 patients/ million. Of all patients studied $72 \%$ were adults with ages between 20-60 years with male preponderance. As a tropical country, tropical diseases such as malaria (27.9\%), diarrhoea (13.6\%) and other infectious diseases were main causes. In the second place come obstructive diseases in both CRF and ARF (26.8\% and $12.9 \%$ respectively) mainly urolithiasis, Scistosomiasis and prostate enlargement. However the cause of CRF in $57.5 \%$ of patients remains unknown as most presented late with ESRF (64.7\%) requiring immediately intervention. Other causes such as Hepatorenal syndrome, snake bite, diabetes mellitus and hypertension were observed but with low occurrence rate. Patients presented to the hospital mostly in severe uraemia and without clear history of medications received before. The most major findings are vomiting, acidosis and hypertension, creatinine range between 2.8 to $45 \mathrm{mg} / \mathrm{dl}$ with mean value $13.4 \mathrm{mg} / \mathrm{dl}$. Anaemia was found in $80.4 \%$ in CRF versus $62.6 \%$ in ARF patients. Hypertension prevalence was $65.5 \%$ in CRF patients, of whom $25 \%$ were in hypertensive crisis whereas in ARF the prevalence was $26.5 \%$ only.

\section{0}

\section{The Effect of Kidney Transplantation Therapy on Renal Anemia in Hemodialysis Patients}

\author{
Y. Takemoto, K. Tsuchida, K. Sugimura, T. Nakatani, \\ T. Kishimoto
}

Osaka City University Graduate School of Medicine, Osaka, Japan

Background: In humans, creatine content is used to measure erythrocyte life span and erythropoietic capacity, since it rapidly declines as the erythrocyte ages. Erythropoietin therapy is useful in ameliorating renal anemia which is generally accompanied by chronic renal failure but the renal anemia is still existing in hemodialysis patients. It is well known that the renal anemia will be improved by kidney transplantation therapy. Two underlying mechanisms have been proposed to explain the effectiveness of kidney transplantation therapy in ameliorating renal anemia: one is that erythropoietin stimulates erythropoiesis and the other is that it extends the life span of erythrocytes. To elucidate the mechanism underlying the ameliorative effectiveness of kidney transplantation therapy on renal anemia, blood samples were collected from 6 kidney transplanted patients 
and erythrocytic creatine was assessed using the method described by Okumiya et al. Methods: Six kidney transplanted patients gave informed consent to participate in this study. Total RBC counts, reticulocyte counts, hematocrit, hemoglobin and RBC creatine were measured before a kidney transplant and after six months and twelve months. Results: The hematocrit increased after 12 months from the kidney transplantaion, demonstrating an improvement in renal anemia. The hematcrit increased from $31.0 \pm 4.3 \%$ before kidney transplantation to $32.8 \pm 6.2 \% 12$ months after. The reticulocyte counts did not change during in this study. On the other hand, the RBC creatine gradually decreased from $2.23 \pm 0.50 \mathrm{umol} / \mathrm{g} \cdot \mathrm{Hb}$ to $1.99 \pm 0.67 \mathrm{umol} / \mathrm{g} \cdot \mathrm{Hb}$ 12 months after. Conclusion: The kidney transplantation theray improved the renal anemia and prolonged the erythrocytes life span in kidneytransplanted patients.

\section{1 \\ Can ESRD Medical Economy in Japan Escape from Her Tragedy?}

H. Hidai

Department of Urology, Yokohama, Japan

Background: Until April 2002, incentive and quality based payment system including better pay for longer dialysis hours in Japan, achieved best outcomes in the world as lowest 1 year crude death rate of $9.3 \%$. However, owing to economic recession in the 1990 's, decreasing GDP forced the Japanese government to slash the medical budget including ESRD payment. The Ministry of Labor \& Health had abandoned policy of incentive and quality based payment system including dialysis hour dependency and cut $12.3 \%$ of the ESRD payment in April 2002 which might influence dialysis outcomes in the near future necessitating in watching them closely. Methods: Japanese GDP, National Medical Care Expenditure (NMCE) and the statistics of the Japanese Society for the Dialysis Therapy (JSDT) were analyzed for the change in dialysis hours and dialysis quality as 1 year crude death rate, $\mathrm{Kt} / \mathrm{V}$, the number of nurses working in the field of dialysis and yearly KDQOL change. Results: GDP; maximum at 1997 as $¥ 520.1$ billion had fallen to $¥ 497.7$ billion in 2002 . Despite above decrease, NMCE continued to increase from $¥ 29.1$ billion to 31.3 billion. Dialysis hours had steadily fallen from 4.0 in 2001 to 3.94 in 2003 . However, 1 year crude death rate showed no change and kept $9.3 \%$ at 2003 . Although no worsening of the above parameters was shown at present, we must be alert for deterioration of the dialysis quality in the future.
32

Low Protein Vegetarian Diet with

Alpha-Cheto Analogues: A Bridge to

the Pre-Emptive Pancreas-Kidney

Transplantation

E. Mezza, D. Motta, V. Consiglio, G. Martina, M. Gai,

M. Burdese, G. Soragna, F. Tattoli, E. Maddalena,

A. Jeantet, G.P. Segoloni, G.B. Piccoli

Chair of Nephrology, Internal Medicine Department, University of Turin, Turin, Italy

Background: Pre-emptive pancreas-kidney transplantation is increasingly considered the best therapy for irreversible chronic kidney disease (CKD) in type 1 diabetics. The best approach in the wait for transplantation is however not defined. Aim: to review our experience with low protein $(0.6 \mathrm{~g} / \mathrm{Kg} /$ day $)$ vegetarian diet supplemented with alfachetoanalogues in type 1 diabetic patients in the wait for pancreas-kidney transplantation. Methods: Prospective study. Data on progression or renal disease, compliance, metabolic control, reasons of choice and of drop-out were recorded prospectively and descriptively analysed in this report for the subset of cases in which the diet was prescribed in the wait for pancreas kidney graft. Results: Since November 1998, to April 2004, 9 type 1 diabetic patients, wait-listed or performing tests for wait-listing for pancreas-kidney transplantation experienced this diet. All were followed by nephrologists and diabetologists, in the context of integrated care. There were 4 males and 5 females; median age 38 years (range 27.9-45.5); median diabetes duration 23.8 years (range 16.633.1), 8/9 with widespread organ damage; median creatinine at diet start: $3.2 \mathrm{mg} / \mathrm{dl}(1.2-7.2)$; 4 patients followed the diet to transplantation, 2 are presently on the diet, 2 dropped-out and started dialysis after few months, 1 started dialysis (rescue treatment). Nutritional status remained stable, glycaemic control improved in 4 patients in the short time and in 2 in the long-time, no hyperkaliemia, acidosis or other relevant side effect was recorded. Proteinuria decreased in 5 cases, in 3 from the nephrotic range. Albumin levels remained stable, progression rate was calculated as loss of $0.64 \mathrm{~mL} / \mathrm{min}$ of creatinine clearance per month (ranging from an increase of 0.36 to a decrease of $1.71 \mathrm{~mL} / \mathrm{min}$ ) by means of Creatinine clearance, based on 24 hours urine collection. Conclusion: Low-protein supplemented vegetarian diets may be a useful tool to slow CKD progression in the wait for pancreas-kidney transplantation.

33

Withdrawal from Dialysis and End of Life Care

\author{
J. Tan, R. Lewis, A. Webb \\ Department of Nephrology, Hull Royal Infirmary, UK
}

Background: Withdrawal of dialysis is a common cause of death amongst the dialysis population. The aim of this project was to determine the frequency of withdrawal of dialysis in our patients, analyse patient characteristics and assess our end of life care. Results: There were 22 deaths related to dialysis withdrawal; a rate of $22 \%$. 
$12 \mathrm{M}$, mean age 77.4 y. 17 patients were on chronic dialysis whilst 5 were dialysed for acute renal failure. Co-morbidity was common; $35 \%$ having ischaemic heart disease, and $25 \%$ heart failure. The main reasons for withdrawing dialysis were frailty/dementia (45\%), sepsis $(27 \%)$, heart failure (18\%) and cancer $(9 \%)$. In 17 (77\%) cases, the decision was made by the medical staff. In the remainder the patient requested withdrawal. The decision was discussed with relatives in $21(95 \%)$, the patient in $10(45 \%)$. Review revealed that unnecessary medication, blood tests and observations were stopped in $41 \%, 86 \%$ and $22 \%$ of cases respectively. DNR orders were in place for 20 patients. Medication for pain, nausea, agitation and secretions were prescribed on an as required basis in these patients in $87 \%, 41 \%, 14 \%$ and $5 \%$ of cases respectively. The mean and median time to death following withdrawal was 5 and 3 days respectively. Conclusion: Our withdrawal rate of dialysis $(22 \%)$ is similar to other countries. Given the nature of withdrawal, death is predictable and should allow good terminal care. However this study shows that end of life care is often sub-optimal. The use of palliative medication and in particular drugs for agitation and secretions were frequently neglected. We believe that there is need to improve on the end of life care and propose the use of a structured care pathway to manage the dying patient.

\section{4}

\section{Are Calculated GFRs Accurate in Elderly} Patients with Advanced Renal Impairment?

\section{A. Banerjee, R. Kesse-Adu, M. Juszczak, A. Burns \\ Department of Nephrology, Royal Free Hospital, London, UK}

European and North-American guidelines recommend using estimated glomerular filtration rate (GFR) from predictive equations derived from Modification of Diet in Renal Disease (MDRD) in advanced chronic kidney disease (CKD). These formulae require further validation in the elderly with advanced $\mathrm{CKD}^{3}$ Aims: To compare MDRD and MDRD-modified (MDRD1) and CG-equations with 3 or 4 sample 51 chromium-labelled ethylene diaminetetraaceticacid (EDTA)-GFR in the elderly with advanced CKD and develop costeffective criteria for EDTA-GFR referrals. Methods: 164 patients $\geq 70$ years who had 3 or 4 sample GFRs were selected. $92 \mathrm{M}$ mean age $77 \pm 5.2$ years, creatinine $256 \pm 110 \mathrm{umol} / \mathrm{l}$, weight $68.4 \pm 14.7 \mathrm{~kg}$ and albumin $39 \pm 5.4 \mathrm{~g} / \mathrm{dL}$. Group 1: 23 patients $(10 \mathrm{M})$ CKD stage III with GFR $30-60 \mathrm{ml} / \mathrm{min}$ with mean creatinine 115 . Group 2: 54 patients (34 M) with CKD stage IV with GFR $15-30 \mathrm{ml} / \mathrm{min}$ with mean creatinine 199. Group 3: 86 patients ( $49 \mathrm{M})$ with CKD stage V with GFR $<15 \mathrm{ml} / \mathrm{min}$ and mean creatinine 329 .

\begin{tabular}{llrr}
\hline & $\begin{array}{l}\text { Group 1 } \\
(\mathrm{ml} / \mathrm{min})\end{array}$ & $\begin{array}{l}\text { Group 2 } \\
(\mathrm{ml} / \mathrm{min})\end{array}$ & \multicolumn{1}{c}{$\begin{array}{l}\text { Group 3 } \\
(\mathrm{ml} / \mathrm{min})\end{array}$} \\
\hline Mean EDTA-GFR & $44.2 \pm 9.8$ & $21.4 \pm 4.2$ & $10 \pm 2.8$ \\
Mean CG & $46.2 \pm 16.3$ & $27 \pm 8.6$ & $15.9 \pm 5.9$ \\
Mean MDRD & $48.8 \pm 15.9$ & $27.96 \pm 8.4$ & $15.9 \pm 5.5$ \\
Mean MDRD1 & $51.8 \pm 18.9$ & $29.5 \pm 8.7$ & $16.8 \pm 6$ \\
\hline
\end{tabular}

Correlation coefficients between EDTA-GFR and CG, MDRD and MDRD1 clearances/GFR were respectively $0.7,0.69,0.69$ in Group 1, 0.26, 0.48, 0.46 respectively in Group 2 and 0.42, 0.47, 0.46 respectively in Group 3. Conclusion: We conclude in patients aged $\geq 70$ with advanced CKD calculated clearances/GFR from formulae like CG or MDRD/MDRD1 are inaccurate. In such patients with similarly derived clearances/GFR $30 \mathrm{ml} / \mathrm{min}$ or higher, more accurate assessments are probably unnecessary.

\section{5 \\ Changes in Tissue Factor (TF) and its Inhibitor (TFPI) during Hemodialysis with Polyacrylonitrile (PAN) and Polysulphone (PS) Membranes}

\author{
P. Zemanova, K. Opatrny Jr., L. Vit, F. Sefrna \\ Department of Medicine I, Pilsen, Czech Republic
}

The aim of the study was to find out (1) how the plasma levels of TF and TFPI, factors playing a crucial role in thrombosis development, change during hemodialysis (HD) and (2) whether or not the changes differ between a new PAN membrane (AN69ST) and a new PS membrane (Helixone). In a randomized prospective crossover study, $\mathrm{TF}$ and TFPI (ELISA) were determined at minutes 0, 15, 60, and 240 of HD in 10 patients using either membrane under identical conditions with unfractionated heparin. Compared with time $0, \mathrm{TF}$ rose significantly at minute 240 both with the PAN (30.0 vs $33.5 \mathrm{ng} / \mathrm{L}$, medians; $\mathrm{p}<0.05$, Wilcoxon) and PS membranes ( 25.0 vs $50.5 \mathrm{ng} / \mathrm{L} ; \mathrm{p}<0.01$ ). TFPI was significantly higher at minute 15 (PAN: 155.0 vs $401.0 \mu \mathrm{g} / \mathrm{L} ; \mathrm{p}<$ 0.01 ; PS: 144.5 vs $522.0 \mu \mathrm{g} / \mathrm{L} ; \mathrm{p}<0.01$ ) and then at minute 60 (PAN: 327.0, $\mathrm{p}<0.05$; PS: 491.0; $\mathrm{p}<0.05$ ), whereas there was no difference at minute 240 (PAN: 152.0, $\mathrm{p}=1$; PS: 170.0, $\mathrm{p}=0.45$ ). The comparison of the 2 membranes did not demonstrate significant differences in TF or TFPI at any of the collecting intervals. The established markers of thrombogenicity and/or anticoagulation (thrombin-antithrombin III complexes, platelet factor 4, activated partial thromboplastin time, and heparin levels) did not differ between the membranes either. Conclusions: The plasma levels of TF and TFPI rise significantly during HD. The dynamics of TF and TFPI changes varies and seems to reflect the thrombogenic action of the membranes and the degree of anticoagulation. Under standard clinical conditions, the new AN69ST PAN and Helixone PS membranes do not differ in their effects on TF and TFPI or on standard thrombogenicity markers.

36

\section{Thrombogenicity and Biocompatibility in CVVHDF with Regional Citrate Anticoagulation}

\author{
K. Polanska, K. Opatrny Jr., R. Rokyta Jr., L. Vit \\ Department of Medicine I, Pilsen, Czech Republic
}

The study was designed to assess the principal markers of thrombogenicity and biocompatibility during CVVHDF using regional citrate anticoagulation. Ten severely ill patients (APACHE II $25 \pm 1.5$, mean \pm SEM) with acute renal failure and impaired hemostasis (decrease in 
thrombocyte count, increased plasma beta-thromboglobulin, D dimer, and shortened aPTT) were examined prospectively in 12 procedures with polysulphone membrane at times $0,15,360$, and 1,440 minutes. Compared with the baseline value of $179.1 \pm 5.7 \mathrm{sec}$, activated clotting time in systemic blood of patients did not rise significantly during the procedure and, together with significant prolongation of aPTT in extracorporeal circuit at filter outlet (before calcium administration) confirmed a limited effect of anticoagulation on extracorporeal circuit. Compared with baseline, a significant decrease in leukocyte count $(17.1 \pm 2.7$ vs $15.3 \pm 2.5 \times 10 \mathrm{E}+9 / \mathrm{L}, \mathrm{p}<0.01, \mathrm{t}$ test $)$ and an increase in plasma C5a $(2.3 \pm 0.6$ vs $6.8 \pm 2.0 \mu \mathrm{g} / \mathrm{L}, \mathrm{p}<0.05)$ were observed at 15 minutes at filter outlet just before calcium-induced reversal of the effect of citrate. Compared with baseline, there was a significant rise in the plasma levels of $\mathrm{D}$ dimer at minute $360(2,810 \pm$ $1,134$ vs $3,650 \pm 1,488 \mu \mathrm{g} / \mathrm{L}, \mathrm{p}<0.05)$. However, the difference in the inlet and outlet levels of D dimer was non-significant, not supporting a role of bioincompatibility in their increase. Blood thrombocyte count, plasma levels of thrombin-antithrombin III complexes, betathromboglobulin and von Willebrand factor did not differ significantly from baseline at any of the collecting intervals. Conclusions: Regional citrate anticoagulation effectively prevents hemostasis activation during CVVHDF. Mild complement activation and a decrease in blood leukocyte count due to the interaction of blood with artificial surface are not eliminated by regional citrate anticoagulation.

37

A Comparison between Two Methods to Assess Intradialytic Hypotension (IDH) and Dialysis Tolerance (DT)

\section{Kanaa, E. Lindley, M. Wright, E. Will \\ Department of Renal Medicine, St. James's University Hospital, Leeds, UK}

Background: There is no widely used, validated, objective measure of DT. We developed a qualitative symptom scoring system (SS) for intradialytic symptoms, with the dialysis nurse recording patient reported severity scores (vomiting, headache, cramp, low BP and feeling unwell. Unfortunately, the SS was not complete in $12 \%$ of 1,426 sessions and patients tended to give the same scores after every session. We felt that an intervention scoring system (IS) would be easier for the nurses to complete and more objective in identifying unstable patients. The IS scored 'reduced UF/ head tilt down', 'saline infusion', 'colloid infusion' and 'early termination of treatment' on a scale of 0-3 depending on the frequency of each intervention. Objective: To compare the two systems and assess their ability to identify patients with IDH as a marker of DT. Methods: Over 5 weeks, 25 established HD patients ( 8 diabetic) had their SS and IS recorded. IDH was defined as: $\mathrm{SBP} \leq 90$ if predialysis $\mathrm{SBP}>100, \leq$ predialysis $\mathrm{SBP}-10$ if this was $\leq 100$, or a decrease of $\geq 33 \%$ if predialysis SBP $>135 \mathrm{mmHg}$. Results: 380 dialysis sessions were reviewed; IS and SS were not been complete in $3(0.7 \%)$ and $23(6 \%)$ sessions respectively $(\mathrm{P}<0.0001)$. IDH occurred in $152(40 \%)$ sessions, symptoms recorded in 108 (71\%) and interventions in $118(78 \%)(\mathrm{P}=\mathrm{NS})$. IS correlated with $\mathrm{SS}(\mathrm{r}=0.5$, $\mathrm{p}<0.0001)$ with 'low BP' $(\mathrm{r}=0.54, \mathrm{p}<0.0001)$ and 'vomiting' $(\mathrm{r}=0.31, \mathrm{p}<0.0001)$ most likely to be associated with interventions.
When the SS and IS of sessions with IDH were compared, a bias of 0.17 points $(95 \% \mathrm{CI} \pm 0.22)$ was found, indicating good agreement. Conclusion: IS was not significantly better at identifying IDH than $\mathrm{SS}$, however it does appear to be more acceptable to dialysis unit staff, and can be computerised.

38

\section{Acute Complications during Haemodialysis are Influenced by Alterations in Blood Pressure Regulation}

\author{
M. Iqbal', R.M. Hossain², H. Rahman², S. Das², \\ M.S. Islam , M.N. Islam³, M.A. Mansur ${ }^{3}$, M. Mohsin ${ }^{1}$ \\ ${ }^{1}$ SSMC and Mitford Hospital, ${ }^{2}$ BSM Medical University, \\ ${ }^{3}$ BIRDEM Hospital, Dhaka, Bangladesh
}

Side effects of HD occur frequently and these influence the shortterm and long-term outcomes. This observational study evaluated frequency of acute complications during HD and their association with other clinical and biochemical parameters. 46 maintenance HD patients, mean age $39 \pm 13 \mathrm{yr}$, body mass index (BMI) $21 \pm 4 \mathrm{~kg} / \mathrm{m}^{2}$, duration of hemodialysis $41 \pm 29$ months, were studied over 3 months. Systolic blood pressure (SBP) $159 \pm 18$ vs $163 \pm 22(\mathrm{p}<0.05)$ and diastolic blood pressure (DBP) $92 \pm 13$ vs $87 \pm 7 \mathrm{mmHg}(\mathrm{p}<0.003)$ before and at the end of dialysis sessions. Single session Kt/V $0.95 \pm$ 0.4 , and ultrafiltration (UF) 2.391 (0.5-4). The rising tendency of postdialysis SBP correlated positively with ultra filtrate (SBP vs UF: $r=0.34, p<0.01)$. Other correlations were between BMI and creatinine $(r=0.36, p<0.05)$ however there was a negative correlation between BMI and $\mathrm{Kt} / \mathrm{V}(\mathrm{r}=-0.39, \mathrm{p}<0.05)$. Correction of acidosis was better in adequately dialyzed patients $\left(\mathrm{HCO}^{-3} \mathrm{vs} \mathrm{Kt} / \mathrm{V}: \mathrm{r}=0.48\right.$, $\mathrm{p}<0.01)$. Acute complications during HD were headache $(75 \%)$, rise in SBP $(73 \%)$, cramps $(67 \%)$, vomiting $(60 \%)$, palpitation $(58 \%)$, sweating (52\%), and hypotension (35\%). Raised SBP correlated positively with headache $(r=0.50, p<0.01)$ and sweating $(r=0.53$, $\mathrm{p}<0.05$ ). Vomiting and palpitation were greater in low post HD SBP ( $\mathrm{r}=-0.41, \mathrm{p}<0.05, \mathrm{r}=-0.48, \mathrm{p}<0.05$ respectively) and these patients were likely to get inadequate dialysis $(\mathrm{r}=-0.63, \mathrm{p}<0.01)$. Acute complications during HD are significantly related to alteration in blood pressure regulation and optimum control of blood pressure could provide better dialysis. 


\section{Oxidative Stress}

39

\section{Is Modified the Circadian Blood Pressure Profiles after Renal Transplantation?}

\author{
M. Voiculescu, C. Ionescu, G. Ismail, C. Bucsa, O. Iliescu, \\ E. Galice
}

Department of Internal Medicine-Nephrology, Fundeni Institute, Bucharest, Romania

Objective: We evaluated the variability of 24-h ABPM profiles in ESRD patients following renal transplantation (RT). Design and Methods: $20 \mathrm{RT}$ recipients $(\mathrm{M}=16, \mathrm{~F}=4$, mean age $=35.3 \pm$ 11.9 y) with normal renal graft, on triple immunosuppressive therapy (CsA/Ts + MMF + Pdn), have been studied using monitoring over a 24-h period with an automatic non-invasive recorder (ABPM-04 Meditech), at $2.4 \pm 2.1$ months after RT. Results:

\begin{tabular}{|c|c|c|c|}
\hline & Before RT & After RT & $P$ value \\
\hline Serum creatinine $(\mathrm{mg} / \mathrm{dl})$ & 10.14 & 1.4 & 0.000 \\
\hline $\begin{array}{l}24 \mathrm{~h}-\text { mean values } \\
\text { Systolic BP }(\mathrm{mmHg}) \\
\text { Diastolic BP }(\mathrm{mmHg}) \\
\text { HR (beats/min) }\end{array}$ & $\begin{array}{c}146.01 \\
88.7 \\
81.6\end{array}$ & $\begin{array}{r}146.9 \\
94.8 \\
87.3\end{array}$ & $\begin{array}{l}\text { NS } \\
\text { NS } \\
\text { NS }\end{array}$ \\
\hline $\begin{array}{l}\text { Waking period - mean values } \\
\text { Systolic BP } \\
\text { Diastolic BP } \\
\text { HR }\end{array}$ & $\begin{array}{r}146.2 \\
88.8 \\
84.0\end{array}$ & $\begin{array}{r}144.4 \\
93.9 \\
93.3\end{array}$ & $\begin{array}{l}\mathrm{NS} \\
\mathrm{NS} \\
0.03\end{array}$ \\
\hline $\begin{array}{l}\text { Sleeping period - mean values } \\
\text { Systolic BP } \\
\text { Diastolic BP } \\
\text { HR }\end{array}$ & $\begin{array}{r}140.6 \\
87.4 \\
75.9\end{array}$ & $\begin{array}{r}150.7 \\
96.8 \\
77.4\end{array}$ & $\begin{array}{l}\mathrm{NS} \\
0.02 \\
\mathrm{NS}\end{array}$ \\
\hline $\begin{array}{c}\text { Dipper mean BP }(>10 \%) \\
\text { Dipper excessive }(>20 \%) \\
\text { Nondipper mean BP }(<10 \%) \\
\text { Nondipper extreme }(<0 \%)\end{array}$ & $\begin{array}{l}3 / 20 \\
0 / 3 \\
17 / 20 \\
10 / 17\end{array}$ & $\begin{array}{c}0 / 20 \\
0 / 0 \\
20 / 20 \\
12 / 20\end{array}$ & $\begin{array}{l}\text { NS } \\
\text { NS } \\
\text { NS } \\
\text { NS }\end{array}$ \\
\hline $\begin{array}{l}\text { Dipper systolic BP } \\
\text { Dipper excessive } \\
\text { Nondipper systolic BP } \\
\text { Nondipper extreme }\end{array}$ & $\begin{array}{c}4 / 20 \\
0 / 4 \\
16 / 20 \\
10 / 16\end{array}$ & $\begin{array}{l}0 / 20 \\
0 / 0 \\
20 / 20 \\
11 / 20\end{array}$ & $\begin{array}{l}\text { NS } \\
\text { NS } \\
\text { NS } \\
\text { NS }\end{array}$ \\
\hline $\begin{array}{l}\text { Dipper diastolic BP } \\
\text { Dipper excessive } \\
\text { Nondipper diastolic BP } \\
\text { Nondipper extreme }\end{array}$ & $\begin{array}{l}4 / 20 \\
1 / 4 \\
16 / 20 \\
10 / 16\end{array}$ & $\begin{array}{c}1 / 20 \\
0 / 1 \\
19 / 20 \\
13 / 19\end{array}$ & $\begin{array}{l}\text { NS } \\
\text { NS } \\
\text { NS } \\
\text { NS }\end{array}$ \\
\hline $\begin{array}{l}\text { Systolic BP SD }(>11 \mathrm{mmHg}) \\
\text { Diastolic BP SD }(>7 \mathrm{mmHg})\end{array}$ & $\begin{array}{r}9 / 20 \\
19 / 20\end{array}$ & $\begin{array}{r}9 / 20 \\
20 / 20\end{array}$ & $\begin{array}{l}\text { NS } \\
\text { NS }\end{array}$ \\
\hline
\end{tabular}

Conclusions: After $2.4 \pm 2.1$ months post transplantation, on the same antihypertensive medication, $\mathrm{BP}$ values was higher and nocturnal diastolic BP and diurnal HR was even higher. There were no differences between the two recorders for mean BP, diurnal BP and nocturnal sysBP, mean HR and nocturnal HR. The absence of nocturnal dip and abnormal short time variability was quite common in ESRD patients before and after renal transplantation.
40

\section{Altered Nocturnal Decline of Blood Pressure in Patients on Chronic Renal Substitution}

\author{
C. Ionescu, M. Voiculescu, G. Ismail, E. Galice, C. Bucsa, \\ S. Marin, M. Lixandru
}

Department of Internal Medicine-Nephrology, Fundeni Institute, Bucharest, Romania

Objective: Previous studies showed that nondipper pattern of blood pressure (BP) are frequent in ESRD patients. We evaluated the nocturnal decline of blood pressure in 150 ESRD pts. Design and Methods: $24 \mathrm{~h}$ monitoring with automatic non-invasive recorder (ABPM-04 Meditech). Patients were divided in 4 groups (nondialysed, HD, CAPD and renal transplantation (RT)) to establish circadian BP profile. Results: 24-h ABPM recordings were analyzed in 79 nondialysed pts, 18 HD, 13 CAPD and 40 RT. 56 nondialysed pts (70.9\%) had an abnormal nondipper profile, with night decreased values which were lower than $10 \%$ and 23 pts $(29.1 \%)$ had a normal dipper profile, with decreased values by night higher than $10 \%$. 22 pts $(27.8 \%)$ had higher night values (extreme nondipper). Excessive dipper profile, with decreased values by night higher than $20 \%$, was present in $10 \mathrm{pts}$ (1.3\%). Nondipper profile were present in $77.8 \%$ HD (14/18), in $69.2 \%$ CAPD pts $(9 / 13)$ and in $87.5 \%$ RT $(35 / 40)$, not statistically different from nondialysed pts. Extreme nondipper profile was more frequent than in nondialysed pts: $44.4 \%$ in HD, 46.1 in CAPD and $42.5 \%$ in RT, without statistical significance. $22.2 \% \mathrm{HD}$ pts, $30.8 \%$ CAPD pts and $12.5 \%$ RT pts had a dipper profile ( $p>0.05$ ). 1/13 CAPD pts had an excessive dipper profile vs none HD pts or RT pts. Conclusions: The absence of nocturnal BP dip was quite common in ESRD patients, over $70 \%$ from these patients having these BP profile. After the including in chronic renal substitution the nocturnal decline of BP remained altered with no significantly reduction in CAPD (less than 70\%) and no significantly rising in HD (over $75 \%$ ) and RT (over 85\%). Moreover, extreme nondipper BP profile was more frequent in HD, CAPD and RT vs nondialysed pts.

\section{1}

Risk Factors for Increased Intima-Medial Thickness of the Carotid Artery in Hemodialysis (HD) Patients with Regards to Presence or Absence of Diabetes (DM) and Serum Phosphate Levels

\section{E. Ishimura, H. Taniwaki, T. Tabata, Y. Nishizawa \\ Osaka City University, Graduate School of Medicine, Osaka, Japan}

Although arteriosclerosis is known to be more advanced in DM than in non-diabetics, it is not known whether different risk factors for arteriosclerosis are present between DM and nonDM HD patients. Using B-mode ultrasonography, we examined intima-medial thickness (IMT) of the carotid artery, and analyzed the risk factors for arteriosclerosis. A total of 715 HD patients were enrolled (547 non-diabetics, $168 \mathrm{DM}$; 
$441 \mathrm{M}, 274 \mathrm{~F}$, age $60 \pm 8.5 \mathrm{y})$. IMT of the DM was significantly greater $(0.89 \pm 0.03$ vs non-DM $0.81 \pm 0.02 \mathrm{~mm}, \mathrm{p}<0.0001)$. In multiple regression analysis; age, longer duration of $\mathrm{HD}$, higher systolic blood pressure, higher serum total cholesterol and phosphate levels, and the presence of DM $(\mathrm{R} 2=0.124, \mathrm{p}<0.00001)$. Multiple regression analysis in non-DM only, increased IMT was associated with advanced age, longer duration of HD, smoking, higher systolic blood pressure, and higher phosphate levels; while analysis of DM only, increased IMT was significantly, independently associated with increasing age, serum cholesterol and phosphate levels. These results demonstrate that significantly advanced arteriosclerosis is present in DM HD compared to non-DM patients, as shown by IMT measurement by B-mode ultrasonography. Although some of the risk factors for arteriosclerosis are different between DM and non-DM HD, higher serum phosphate levels, in addition to advanced age, are a common, significant risk factor for advanced arteriosclerosis. We demonstrated for the first time that higher phosphate levels are a significant risk factor for advanced arteriosclerosis both in DM and non-diabetic hemodialysis patients.

\section{2 \\ Oxidative Stress and Apoptosis during Low-Flux Hemodialysis (HD) with Two Synthetic Dialysis Membranes}

D.H. Krieter ${ }^{1}$, A. Morgenroth ${ }^{2}$, N. Sauer ${ }^{3}$, H.-D. Lemke ${ }^{3}$, C. Wanner ${ }^{1}$

${ }^{1}$ Nephrology, University of Würzburg, ${ }^{2}$ Dialysis Center Elsenfeld, ${ }^{3}$ Membrana Research, Obernburg, Germany

Oxidative stress and enhanced apoptosis induced by HD are possible factors of increased mortality/morbidity in ESRD patients. In a prospective study on four HD patients ( $\mathrm{m} / \mathrm{f} 3 / 1 ; 65.5 \pm 13.7$ years), the effect of two synthetic low-flux membranes, DIAPES ${ }^{\circledR}$ LF100 (PES; Bellco BLS 517G; $1.7 \mathrm{~m}^{2}$ ) and Polyamix ${ }^{\circledR}$ (PA; Polyflux 17L; $1.7 \mathrm{~m}^{2}$ ), on oxidative stress (oxidative burst activity, generation of peroxides and myeloperoxidase (MPO), antioxidative capacity (AOC)) and apoptosis (Annexin V/Propidiumjodid) during HD was determined. Patients were dialyzed with each membrane thrice for four hours $\left(\mathrm{Q}_{\mathrm{B}} 250 \mathrm{ml} / \mathrm{min} ; \mathrm{Q}_{\mathrm{D}} 500 \mathrm{ml} / \mathrm{min}\right)$. Blood samples were drawn before (art.) and after (ven.) passage of the dialyzer at defined intervals. A maximum increase in 'oxidative burst' was observed $5 \mathrm{~min}$ after the beginning of HD with PA $(2.9 \pm 2.3$ to $10.3 \pm 8.3 \mathrm{MCF}$ ven.) and after $10 \mathrm{~min}$ with PES $(1.8 \pm 1.8$ to $3.8 \pm 6.0 \mathrm{MCF}$ ven. $)$. In contrast, an increase of peroxides was noted during the whole $240 \mathrm{~min}$ treatment (PA $135 \pm 92$ to $318 \pm 164 / 417 \pm 199$ art./ven. $\mu \mathrm{mol} / \mathrm{l}$; PES $136 \pm 118$ to $314 \pm 205 / 412 \pm 260 \mathrm{art} / \mathrm{ven} . \mu \mathrm{mol} / \mathrm{l})$, while AOC decreased respectively (PA $273 \pm 26$ to $246 \pm 34 / 258 \pm$ 31 art./ven. $\mu \mathrm{mol} / \mathrm{l}$; PES $259 \pm 15$ to $237 \pm 14 / 236 \pm 31$ art./ven. $\mu \mathrm{mol} / \mathrm{l})$. MPO generation after the dialyzer peaked at $5 \mathrm{~min}$ (PA $20.4 \pm 5.2$ to $103 \pm 42 \mu \mathrm{g} / \mathrm{l}$; PES $18.4 \pm 4.8$ to $94 \pm 29 \mu \mathrm{g} / \mathrm{l})$. Both membranes decreased apoptotic (PA $31 \pm 5.6$ vs $17.3 \pm 3 \%$; PES $34 \pm 9.3$ vs $21.2 \pm 11.6 \%$ ) and increased vital leukocytes (PA $59 \pm 8.4$ vs $72 \pm 8.6 \%$; PES $54 \pm 13$ vs $66 \pm 20 \%$;) after $240 \mathrm{~min}$. Low-flux-HD is associated with dialysis membrane-induced oxidative stress. In contrast, it leads to a beneficial effect on apoptosis.
43

\section{Abnormalities of Cellular Immunity in Uremic Patients Receiving Hemodialysis (HD)}
I. Griveas, G. Visvardis, A. Fleva, D. Papadopoulou,
E. Mitsopoulos, P. Kyriklidou, E. Manou, E. Ginikopoulou,
D. Meimaridou, A. Pavlitou, G. Sakellariou

Nephrology Department and Immunology Department,

Papageorgiou General Hospital, Thessaloniki, Greece

Background: $\mathrm{T}$ lymphocyte activation after leukocyte membrane interaction may play a role in immune dysfunction associated with HD. In order to clarify the abnormalities of cellural immune responses in HD patients, we studied as immunological parameters lymphocytes subsets counts. Methods: 45 healthy volunteers and 34 patients on HD therapy were recruited for the present study. Lymphocyte subpopulations (CD2, CD3, CD3+/CD4+, CD3+/ $\mathrm{CD} 8+, \mathrm{CD} 3-/ 16+56+, \mathrm{CD} 19, \mathrm{CD} 4 / \mathrm{CD} 8)$ were determined by flow cytometry. Statistical evaluation was made by Student's t-test. Results: Lymphopenia, decreased absolute counts, and altered percentage values of immune cells were found $(27.24 \pm 7.37 \mathrm{vs}$ $31.79 \pm 7.31, \mathrm{p}<0.05)$. Increased proportions of CD2 $(82.68 \pm$ 7.06 vs $80.14 \pm 4.67, \mathrm{p}<0.05) \mathrm{T}$ lymphocytes were present. An abnormally low percentage of CD3 (70.45 \pm 8.9 vs $73.71 \pm 5.78$, $\mathrm{p}=\mathrm{NS}), \mathrm{CD} 3 / 4(41.58 \pm 9.02$ vs $45.20 \pm 6.65, \mathrm{p}<0.05)$ was also seen in HD patients. The proportion of B lymphocytes was found to be significantly lower as compared with controls $(6.80 \pm 4.95$ vs $12.32 \pm 3.44, \mathrm{p}<0.05)$. HD patients showed increased natural killer cells than controls $(16.96 \pm 7.60$ vs $10.3 \pm 4.10, p<0.05)$. The $\mathrm{CD} 4+/ \mathrm{CD} 8+$ ratio showed no significant change $(1.88 \pm 1.20 \mathrm{vs}$ $2.01 \pm 0.72, p=N S)$. Conclusion: We conclude that profound quantitative alterations of immune cells exist in HD patients. These account, at least in part, for the immune dysregulation associated with chronic renal failure. These results may explain the increased vulnerability to infections in HD patients compared with healthy subjects. Additionally increased natural killer cells may reflect chronic sterile or infectious inflammatory response.

44

\section{Association between Inflammation, Endothelial Cell Adhesion Molecules and Atherosclerosis in End Stage Renal Disease (ESRD)}

\author{
A. Papagianni, M. Kalovoulos, A.-M. Belechri, \\ D. Memmos \\ University Department of Nephrology and Department \\ of Radiology, Hippokration General Hospital, \\ Thessaloniki, Greece
}

Recent studies suggest a strong association between inflammation and atherosclerosis in ESRD patients but the underlying mechanisms are not well understood. However, inflammation up-regulates the expression of endothelial adhesion molecules which is considered a 
key event in the development of atherosclerosis. Eighty-five ESRD patients prior to the start of haemodialysis (HD) treatment, 91 patients on HD and 65 age and sex-matched controls participated in the study. The degree of atherosclerosis was assessed by measuring intimamedia thickness (IMT) of the common carotid arteries using an ultrasound scanner. Compared with controls, ESRD and HD patients had significantly increased serum CRP, ICAM-1 and VCAM-1 (each $\mathrm{p}<0.0001$ ), as well as IMT values (each $\mathrm{p}<0.001$ ). Moreover, compared with ESRD, HD patients had increased serum CRP, ICAM-1 and VCAM-1 ( $<<0.001, \mathrm{p}<0.001$ and $\mathrm{p}<0.0001$ respectively) and IMT $(p<0.05)$. Significant correlations were observed between $\log$ CRP and ICAM-1 and VCAM-1 levels in ESRD $(p=0.003$ and $\mathrm{p}=0.001$ respectively) and HD patients $(\mathrm{p}=0.0004$ and $\mathrm{p}=0.001$ respectively) In univariate analyses, IMT was correlate with age, systolic blood pressure, history of cardiovascular disease (CVD), log CRP and ICAM-1 levels in ESRD ( $p=0.0001, p=0.01, p=0.03, p=0.02$ and $\mathrm{p}=0.004$ respectively) and HD patients $(\mathrm{p}=0.0001, \mathrm{p}=0.01$, $\mathrm{p}=0.02, \mathrm{p}=0.02$ and $\mathrm{p}=0.001$ respectively). Multivariate analyses showed that ICAM-1 was a strong independent correlate of IMT in ESRD and HD patients ( $p=0.001$ and $p=0.001$ respectively). Moreover, compared with patients with normal IMT, ESRD and HD patients with increased IMT $(>0.82 \mathrm{~mm})$ had increased ICAM-1 $(\mathrm{p}<0.01$ and $\mathrm{p}<0.001$ respectively). In addition, compared with patients with a negative history, ESRD and HD patients with CVD had increased ICAM-1 ( $p<0.05$ and $p<0.005$ respectively) and IMT ( $p<0.01$ and $\mathrm{p}<0.005$ respectively). In conclusion, in ESRD patients serum ICAM-1 levels are linked to an inflammatory state and are useful surrogate marker of atherosclerosis. HD treatment appreared associated with further activation of the inflammatory response and acceleration of atherosclerosis.

\section{5 \\ On-Line Hemodiafiltration (HDF) does not Induce Inflammatory Response in End-Stage Renal Disease Patients: Results from a Multicenter Cross-Over Study}

L.R. Vaslaki ${ }^{1}$, K. Berta ${ }^{2}$, L. Major ${ }^{3}$, V. Weber ${ }^{4}$, C. Weber ${ }^{5}$, R. Wojke ${ }^{5}$, J. Passlick-Deetjen ${ }^{5}$, D. Falkenhagen ${ }^{4}$

${ }^{1}$ 2nd Medical School, University of Debrecen, and Erzsébet Hospital Sopron, ${ }^{2} 1$ st Department of Medicine, Semmelweis University Budapest,

${ }^{3}$ Fresenius Medical Care Dialysis Centre Esztergom, Hungary, ${ }^{4}$ Christian Doppler Laboratory for Specific Adsorption Technologies in Medicine, and Centre for Biomedical Technology, Danube University Krems, Austria, ${ }^{5}$ Fresenius Medical Care, Bad Homburg, Germany

On-line HDF, represents the most efficient blood purification modality for end-stage renal disease (ESRD) patients. Large-volume infusion of on-line prepared substitution fluid may, however, expose patients to inflammatory contaminants and might aggravate chronic inflammation. In a multicenter cross-over study, 27 ESRD patients were randomly assigned to 6 month treatment with on-line HDF and low-flux hemodialysis (HD) with polysulfone membranes and ultrapure dialysis fluid, and then crossed to the other treatment modality, for another 6 months. Inflammatory parameters were elevated in the study population compared to healthy controls. Induction of IL-1Ra and TNF $\alpha$ was comparable for on-line HDF and low-flux HD $\left(209 \pm 48\right.$ vs $145 \pm 30$ and $11 \pm 1$ vs $27 \pm 14$ pg/10 $0^{6} \mathrm{WBC}$, respectively), and there was no intradialytic increase in cytokine production. As a result, IL-6 plasma levels were not different (119 \pm 18 vs $120 \pm$ $23 \mathrm{pg} / \mathrm{l})$. Similarly, no difference between on-line HDF and low-flux HD was observed for CRP and serum albumin. Markers of endothelial cell activation, sICAM-1 and SVCAM-1 and troponin T (cTnT) remained elevated compared to healthy subjects, but showed no difference between the two treatment modalities (sICAM-1: $1267 \pm 271$ vs $1256 \pm 195 \mathrm{ng} / \mathrm{ml} ;$ sVCAM-1: $1300 \pm 122$ vs $1263 \pm 108 \mathrm{ng} / \mathrm{ml}$; cTnT: $45 \pm 8$ vs $49 \pm 8 \mathrm{ng} / \mathrm{l})$. In conclusion, on-line HDF does not provoke inflammatory response and performs therefore safely and highly biocompatible.

\section{6 \\ Cardiovascular Mortality and the $-159 \mathrm{C} / \mathrm{T}$ Polymorphism of the Endotoxin Receptor (CD14) Carotid in Dialysis Patients}

\author{
A. Losito' ${ }^{1}$, K. Kalidas ${ }^{2}$, S. Santoni ${ }^{1}$, R. Errico ${ }^{1}$, S. Jeffery ${ }^{2}$ \\ ${ }^{1} \cup O$ Nefrologia e Dialisi, Policlinico Monteluce, \\ Perugia, Italy, ${ }^{2}$ Medical Genetics Unit, St. George's \\ Hospital Medica School, Tooting, London, England
}

Endotoxin has been found frequently in blood of dialysis patients, and it has been considered a risk factor for atherosclerosis. Endotoxin is mainly cleared from plasma by the sCD14, the soluble form of the endotoxin receptor whose concentration is controlled by the $-159 \mathrm{C} / \mathrm{T}$ polymorphism of the CD14 gene (TT $>\mathrm{CC}$ ). We have studied the cardiovascular mortality and its association with the CD14 polymorphism in a cohort of 158 dialysis patients (96 male, 62 female, age $66.9 \pm 13.5$, time on dialysis $57.2 \pm 61.6$ months). BMI was $24.8 \pm$ 4.5 , serum albumin $3.9 \pm 0.47 \mathrm{~g} / \mathrm{dL}$, mean $\mathrm{Kt} / \mathrm{V}$ was $1.33 \pm 0.36$. we found a significant difference in the prevalence of carotid artery disease between groups divided by genotype: CC $87.0 \%$, CT $71.7 \%$, TT $48.9 \%(\mathrm{P}=0.0093)$. The average follow-up was $38.2 \pm 14.5$ months; during this time 48 deaths were recorded. In 33 deaths a cardiovascular cause was detected (cumulative survival $80.3 \% \pm 0.03$ ). The Cox analysis revealed that also cardiovascular survival was influenced by the CD14 polymorphism. The survival in the three genotypes decreased from TT ( $45 \pm 4$ months) to CC (41 \pm 4 months) (log rank test: 4.00, $\mathrm{P}=0.0454)$. These results demonstrate an association between the $-159 \mathrm{C} / \mathrm{T}$ polymorphism of CD14, carotid artery disease and cardiovascular mortality in dialysis patients. We suggest that the low plasma clearance of endotoxin associated with the CC genotype facilitate the atherogenic action on endotoxin-derived cytokines in haemodialysis patients. 


\section{7 \\ Prolonged Oral $\alpha$-Tocopherol \\ Administration Increases \\ Oxidative Stress Markers and \\ Anticardiolipin Antibody Levels in Hemodialysis (HD) Patients

\author{
G. Antoniadi ${ }^{1}$, T. Eleftheriadis ${ }^{1}$, V. Liakopoulos ${ }^{2}$, \\ 1. Stefanidis'2, E. Kakasi ${ }^{3}$, G. Vayonas ${ }^{4}$, \\ A. Kortsaris ${ }^{5}$, V. Vargemezis 6 \\ ${ }^{1}$ Department of Nephrology, General Hospital of Serres, \\ Serres, ${ }^{2}$ Department of Nephrology, University of \\ Thessalia, Larissa, '²aboratory of Biochemistry, General \\ Hospital 'Agios Pavlos', 'Department of Nephrology, \\ B' IKA Hospital, Thessaloniki, 5 Department \\ of Biochemistry, ${ }^{6}$ Department of Nephrology \\ Demokritus University of Thrace, Alexandroupolis, \\ Greece
}

Background: Oxidative stress is increased in patients undergoing HD and may contribute to their increased morbitity and mortality. Patients on HD have also elevated plasma anticardiolipin antibody (ACA) levels. Oxidative stress has been implicated in ACA formation. Vitamin E usually has antioxidative properties. In this study the effects of prolonged oral $\alpha$-tocopherol administration on oxidative stress markers and ACA levels were evaluated. Methods: In 27 clinically stable chronic HD patients plasma total antioxidant status (TAS), red cell superoxide dismutase (SOD) activity and glutathione peroxidase (GPX) activity, were assessed as oxidative stress markers and serum ACA (ACA-IgG and IgM). Measurements were performed before and after one year of oral $\alpha$-tocopherol $(500 \mathrm{mg} / \mathrm{d})$. Oxidative stress markers were assessed by spectrophotometer and ACA levels were assessed by solid-phase enzyme immunoassay. Results: After 12 mo $\alpha$-tocopherol administration a significant decrease in TAS $(1.624 \pm 0.179$ vs $1.421 \pm 0.263 \mathrm{mmol} / 1, \mathrm{p}<0.05)$ and SOD $(1,433 \pm 657$ vs $1,172 \pm 374 \mathrm{u} / \mathrm{grHb}, \mathrm{p}<0.05)$ was observed, whereas the levels of GPX remained unaffected. Administration of $\alpha$-tocopherol lead further to a rise of the ACA-IgG levels from $13.3 \pm 6.64 \mathrm{GPL} / \mathrm{ml}$ to $26.7 \pm 14.7 \mathrm{GPL} / \mathrm{ml}(\mathrm{p}<0.001)$, and the ACA-IgM from $2.96 \pm 4.18$ to $8.17 \pm 1.95 \mathrm{MPL} / \mathrm{ml}(\mathrm{p}<0.001)$. Between the changes in TAS and the changes in ACA-IgG after $\alpha$-tocoferol administration we found a significant negative correlation (Rho $=-0.694, p=0.003$ ). Conclusions: Prolonged oral $\alpha$-tocopherol administration in HD patients has pro-oxidative properties. Vitamin C deficiency and/or the decrease of $\gamma$-tocopherol plasma levels due to oral $\alpha$-tocopherol administration are factors that could explain the pro-oxidative effect of oral $\alpha$-tocopherol.

\section{Peritoneal Dialysis}

\section{8 \\ Peritoneal Dialysis Performance and Incidence of Peritonitis}

\author{
M. Avramovic, R. Velickovic, V. Stefanovic \\ Department of Peritoneal Dialysis, Institute \\ of Nephrology and Hemodialysis, Nis, \\ Yugoslavia
}

Peritonitis is a very serious complication in peritoneal dialysis. Among technical factors associated to peritonitis rate, $\mathrm{Y}$ disconnect system, double bag system and APD are established to reduce incidence of peritonitis. No data in literature deal with dialysis performer and incidence of peritonitis. In the five-years period 67 patients (46 female, 21 male, mean age $52.9 \pm 12.7$ ) starting CAPD and being on program for more than 6 months were analysed. All patients were on CAPD treatment modality with standard glucose containing dialysis solutions on single bag system or ANDY set. Patients were divided in two groups according to dialysis system used: 35 patients on Fresenius single bag system (group F) and 32 patients on ANDY disconnect system (group A). In self-performing dialysis group (S group) there were 34 patients, and 33 in helper group (H group). Patients in $\mathrm{S}$ group were younger than in $\mathrm{H}$ group $(50.6 \pm 12.1$ vs $55.3 \pm 13.0$ years, respectively, $\mathrm{p}=\mathrm{ns}$ ). The number of comorbidity conditions found, was statistically higher in H group: $2.91 \pm 0.54$ vs $1.84 \pm 0.88 ; p<0.001$. The reasons for incapability of self-performance of CAPD in the helper group were: blindness/insufficient vision (4 cases), mental incompetence (3), impaired hand function (2), self-unconfident/inefficient (23 cases). All patients were examined once a year on changes in dialysis adequacy parameters, nutritional indices and peritonitis rate. Data are compared by Student t-test or Chi-square test, as appropriate. Multiple regression analysis was used to identify the factors determining peritonitis rate. All adequacy and nutritional indices examined [residual renal function (RRF), Kt/V, ultrafiltration (UF), standard PET test, dialysis protein loss, serum albumin, SGA] didn't differ significantly between $\mathrm{S}$ and $\mathrm{H}$ group of patients except KT/V. Peritonitis rate was higher in $\mathrm{H}$ group, and occurs earlier than in $\mathrm{S}$ group (Table 1).

Table 1. Peritonitis as function of dialysis performance

\begin{tabular}{llllll}
\hline Performer & $\begin{array}{l}\text { No of } \\
\text { peritonitis }\end{array}$ & $\begin{array}{l}\text { I peritonitis } \\
\text { after } \\
\text { (months) }\end{array}$ & \multicolumn{3}{l}{$\begin{array}{l}\text { Incidence of peritonitis } \\
\text { (/patient year) }\end{array}$} \\
\cline { 4 - 6 } & & $\mathrm{F}$ & $\mathrm{A}$ & $\mathrm{F}+\mathrm{A}$ \\
\hline Patient & 47 & 12.3 & 0.80 & 0.81 & 0.80 \\
Helper & $82^{\mathrm{a}}$ & 7.3 & 1.91 & 1.18 & $1.65^{\mathrm{b}}$ \\
\hline
\end{tabular}

Legend: F: Fresenius single bag, A: ANDY set; ${ }^{\mathrm{a}} \mathrm{vs}$ patient's group $\mathrm{p}<$ $0.05 ;{ }^{\mathrm{b}} \mathrm{vs}$ patient's group $\mathrm{p}<0.0001$.

In this study, peritonitis rate was evaluated according to subject performing dialysis exchanges: patient himself or helper. The incidence of peritonitis was found significantly lower in self-performing dialysis patients than in helper group. This effect was independent of the dialysis system used. 


\section{9 \\ Abnormalities of Cellular Immunity in Uremic Patients Receiving Hemodialysis (HD) and Peritoneal Dialysis (CAPD)}

I. Griveas, G. Visvardis, A. Fleva, D. Papadopoulou,

E. Mitsopoulos, P. Kyriklidou, E. Manou,

D. Meimaridou, E. Ginikopoulou, A. Pavlitou,

G. Sakellariou

Nephrology Department and Immunology

Department, Papageorgiou General Hospital,

Thessaloniki, Greece

Background: To investigate the abnormalities of cellular immune responses in patients on hemodialysis (HD) and in those on continuous ambulatory peritoneal dialysis (CAPD). Methods: Forty-five (45) healthy volunteers, 34 patients on HD therapy and 37 patients on CAPD were recruited for the present study. Lymphocyte subpopulations $(\mathrm{CD} 2+, \mathrm{CD} 3+, \mathrm{CD} 3+/ \mathrm{CD} 4+, \mathrm{CD} 3+/ \mathrm{CD} 8+, \mathrm{CD} 3-/ 16+56+$, CD19, CD4/CD8) were determined by flow cytometry. Results: Lymphopenia, decreased absolute counts, and altered percentage values of $\mathrm{CD} 3+, \mathrm{CD} 3+/ 4+, \mathrm{CD} 19+$ subpopulations were found in both patient groups. HD and CAPD patients showed increased percentages of natural killer cells $(\mathrm{CD} 3-/ 16+56+)$ compared to controls but $\mathrm{CD} 4+/ \mathrm{CD} 8+$ ratio showed no significant changes among uremic patients and controls. Conclusion: Replacement therapy may contribute to the quantitative alterations of immune subsets found in $\mathrm{HD}$ and CAPD patients compared to normal subjects. We speculate that these changes account, at least in part, for the immune dysregulation observed in patients with chronic renal failure. Analysis of lymphocyte subsets will help the research and the evaluation of the possible causes of immunodeficiency in uremic patients under replacement therapy and will probably contribute to more efficient and preventive strategies.

\section{0}

\section{Analyses of Factors Influencing Hemoglobin Level in CAPD Patients in a Local centre in Hong Kong}

\author{
C.-K. Chan, S.H.-K. Lo, H.-P. Shum, V. Chow, \\ S.K.-L. Mo, K.-S. Wong \\ Division of Nephrology, Department of Medicine, \\ Pamela Youde Nethersole Eastern Hospital, HKSAR, \\ Hong Kong
}

Background: The treatment of recombinant human erythropoietin (r-Hu-EPO) has been clearly shown to improve anaemia in continuous ambulatory peritoneal dialysis (CAPD) patients. The aim of this study is to identify factors associated with anemia in CAPD patients. Optimizing these factors might improve the cost effectiveness in using recombinant human erythropoietin. Methods: CAPD patients in a local dialysis centre were retrospectively reviewed. Baseline demographic data, laboratory data (hemoglobin level $(\mathrm{Hb})$, albumin, calcium and phosphate level, parathyroid hormone and iron profile), dialysis adequacy (Kt/v (peritoneal and total), residual renal function (RRF), nutritional protein catabolic rate (nPCR)), as well as dosages for oral iron supplement and r-Hu-EPO (recombinant human erythropoietin beta) were all recorded for statistical analysis. Iron saturation was defined as $\mathrm{Fe} / \mathrm{TIBC} \times 100$. Results: One Hundred forty male and 82 female CAPD patients were included in this study. Mean age $=63.7 \pm 12.4$ yrs. One hundred and seventeen patients had diabetic mellitus (52.7\%). Mean hemoglobin $(\mathrm{Hb})$ level was $9.0 \pm 1.6 \mathrm{gm} / \mathrm{dl} .72$ patients $(32.4 \%)$ were put on $\mathrm{r}$-Hu-EPO (mean dose $=4347$ unit/week), and $103(46.4 \%)$ patients were put on oral iron supplement $\left(\mathrm{FeSO}_{4}\right)$, with mean dose of $510 \mathrm{mg} /$ day $(165.75 \mathrm{mg}$ elemental Fe/day). Positive correlations were found between $\mathrm{Hb}$ level and RRF (Pearson correlation $(r)=0.189, p=0.016$ ) and between $\mathrm{Hb}$ and albumin level $(\mathrm{r}=0.220, \mathrm{p}=0.001)$. A negative correlation was found between $\mathrm{Hb}$ level and ferritin level $(\mathrm{r}=-0.189, \mathrm{p}=0.01)$. There was no correlation between $\mathrm{Hb}$ level and Iron saturation $(\mathrm{p}=\mathrm{NS})$ and $\mathrm{Hb}$ level and daily oral iron $(\mathrm{r}=-0.137, \mathrm{p}=0.051)$. On the other hand, r-Hu-EPO dose was correlated negatively with $\mathrm{Kt} / \mathrm{V}$ (total) $(\mathrm{r}=-0.206, \mathrm{p}=0.008)$. In addition, RRF was correlated with higher nPCR $(r=0.290, p=0.000)$, higher albumin $(r=0.158$, $\mathrm{p}=0.043)$, lower calcium phosphate product $(\mathrm{r}=-0.249, \mathrm{p}=0.001)$ and with lower $r-H u-E P O$ dose $(r=-0.225, p=0.004)$. Regression analyses confirmed linear relation between RRF and r-Hu-EPO dose per body weight per week $(b=-0.225, r=0.004)$, albumin and $\mathrm{Hb}(\mathrm{b}=0.09, \mathrm{p}=0.005)$, as well as RRF and Hb level $(\mathrm{b}=0.189$, $\mathrm{p}=0.016)$. Patients with $\mathrm{Kt} / \mathrm{V}$ (total) less than 1.7 required higher r-Hu-EPO dose when compared to those with $\mathrm{Kt} / \mathrm{V}$ greater than 1.7 (46.50 vs 22.69 units/Kg/week, $\mathrm{p}=0.002$ ). Anuric patients required higher $\mathrm{r}-\mathrm{Hu}-\mathrm{EPO}$ dose than those with residual renal function $(59.9 \mathrm{vs}$ $23.92 \mathrm{unit} / \mathrm{Kg} /$ week, $\mathrm{p}=0.001$ ). The plot of $\mathrm{r}-\mathrm{Hu}-\mathrm{EPO}$ dosage against $\mathrm{Kt} / \mathrm{V}$ (total) showed inverse relation, which was confirmed by linear regression between $\mathrm{r}-\mathrm{Hu}-\mathrm{EPO}$ dosage and recipical of $\mathrm{Kt} / \mathrm{V}$ (total) $(b=0.45, p=0.001)$. Conclusion: $\mathrm{Hb}$ level was correlated with positively with $\mathrm{Kt} / \mathrm{V}$ and residual renal function. Lower $\mathrm{r}-\mathrm{Hu}-\mathrm{EPO}$ dosage was correlated with $\mathrm{Kt} / \mathrm{V}$ (total) and higher residual renal function. Maintaining dialysis adequacy and preserving residual function might improve anemia and reduce erythropoietin dose in CAPD patients with anemia. Further larger scale studies are required to establish the interrelationship among dialysis adequacy, iron profile, r-Hu-EPO dosage and $\mathrm{Hb}$ 
51

\section{Increasing Our Understanding of the Mechanism of Action of Icodextrin (ICO)}

\author{
S.J. Davies', G. Woodrow², K. Donovan³, J. Plum4, \\ P. Williams, ${ }^{5}$ A.C. Johansson ${ }^{6}$, H.-P. Bosselmann , \\ O. Heimburger ${ }^{8}$, O. Simonsen $^{9}$, A. Davenport ${ }^{10}$, \\ A. Tranaeus ${ }^{11}$, J.C.D. Filho ${ }^{11}$ \\ ${ }^{1}$ University Hospital of North Staffordshire, \\ Stoke-on-Trent, ${ }^{2}$ Leeds Teaching Hospitals Trust, \\ Leeds, ${ }^{3}$ Morriston Hospital, Swansea, UK, ${ }^{4}$ Klinik für \\ Nephrologie, Düsseldorf, Germany, ${ }^{5}$ Addenbrookes \\ Hospital, Cambridge, UK, ${ }^{6}$ Sahlgrenska Sjukhuset, \\ Goteborg, Sweden, ${ }^{7}$ Otto-von-Guericke-Universität, \\ Magdeburg, Germany, ${ }^{8}$ Karolinska Institutet, Huddinge \\ University Hospital, Stockholm, ${ }^{9}$ University Hospital of \\ Lund, Sweden, ${ }^{10}$ Royal Free Hospital, \\ London, UK, ${ }^{11}$ Baxter S.A, Brussels, Belgium
}

We have shown in a randomized double blind trial that ICO reduces the fluid volume in the extra-cellular (ECF) space with relative preservation of residual renal function (RRF). To explore mechanisms of this fluid shift we analysed prospective data on inflammation (CRP, TNF- $\alpha$ ), intra-vascular volume (ANP), osmolality and low/high molecular weight hyaluronan (L/HMW-HA), which reflects inflammation and the rate of fluid shift from the ECF to vascular space. 50 pts were randomised to $2.27 \%$ glucose $(\mathrm{G})$ or ICO for the long PD dwell after a month run in. Blood samples for CRP, TNF- $\alpha$, ANP and L/HMW-HA were taken at $-1,0,3$ and 6 mos. Correlations with changes in ECF and RRF were made. In both groups a significant relationship between fall in ECF volume and RRF was observed. The relative drop in urine volume for ICO pts was significantly less $(400 \mathrm{mLs}$ less /L change in $\mathrm{ECF})$. At baseline ANP was higher in pts with more ECF, (ECF:TBW ratio), $\mathrm{r}=0.35 \mathrm{P}=0.026$. ICO pts had higher ANP levels throughout the study, $\mathrm{P}=\mathrm{NS}$ at baseline, whereas by $3(\mathrm{P}=0.026)$ and $6 \mathrm{mos}$ $(\mathrm{P}=0.016)$ this was different between groups. There was a correlation between increasing ANP and reduced ECF at 3 mos, $R=-0.46$, $\mathrm{P}=0.007$, in ICO but not $\mathrm{G}$ pts. In both groups, TNF- $\alpha$ correlated with high but not low MW-HA. There were no relationships between fluid status (ECF:TBW) and inflammatory markers, except albumin at baseline, $\mathrm{R}=-0.3, \mathrm{P}=0.02$. ICO pts had a significant and sustained increase in $\mathrm{H}$ and LMW-HA, $(\mathrm{P}=0.015$ at $3 \mathrm{mos}, \mathrm{P}=0.008$ at $6 \mathrm{mos}$ ), not seen in G pts. TNF- $\alpha$ increased in G pts by $6 \mathrm{mos}$, $\mathrm{P}=0.03$. Plasma osmolality was higher in ICO pts post intervention, $\mathrm{P}=0.056$ at $3 \mathrm{mos}$. These data suggest that ICO alters fluid status by enhancing ultrafiltration and changing fluid distribution between ECF and intra-vascular space. We propose that ICO metabolites in the circulation encourage a fluid shift from the ECF space, maintaining intra-vascular volume, protecting against loss of RRF. The increase in plasma L/HMW-HA cannot be explained by increased inflammation and may reflect enhanced flow from the ECF space.
52

\section{Continuous Flow PD (CFPD) in a Patient with Acute Renal Failure (ARF) and Anasarca}

R. Amerling ${ }^{1}$, C. Oleru ${ }^{1}$, I. Malostovker ${ }^{1}$, A. Dubrow ${ }^{1}$, P. Mayo ${ }^{2}$, S. Sundaram ${ }^{2}$

'Division of Nephrology and Hypertension, Beth Israel Medical Center, New York, NY, '2Division of Pulmonary/ Critical Care, Beth Israel Medical Center,

New York, NY, USA

CFPD has been used in the management of chronic renal failure and dialysis ascites. We report an experience using this technique in a patient with acute renal failure, severe hypoalbuminemia, ascites and anasarca. A 66-yr-old woman developed ARF in the setting of thyroid storm, and multi-drug resistant sepsis. She became massively edematous and hypoalbuminemic (albumin 1.2/dl) and was hemodynamically unstable with minimal ultrafiltration during slow continuous hemodialysis. Two pigtail catheters were inserted percutaneously into opposite quadrants of the abdomen under local anesthesia and ultrasound guidance. CFPD was initiated using ascites recirculation through a Fresenius F160NR dialyzer using the Fresenius 2008H machine in CRRT mode. Ascites was cycled at $200 \mathrm{ml} / \mathrm{min}$. Dialysate with $4 \mathrm{mEq} / 1 \mathrm{~K}$, and $2.5 \mathrm{mEq} / 1 \mathrm{Ca}$ was sent through the external circuit at $300 \mathrm{ml} / \mathrm{min}$, later lowered to $100 \mathrm{ml} / \mathrm{min}$. Ultrafiltration was $50-200 \mathrm{ml} / \mathrm{hr}$. After 24 hours, 3.6 liters of fluid had been removed. BUN decreased from 54 to $22 \mathrm{mg} / \mathrm{dl}$, and creatinine from 1.7 to $0.7 \mathrm{mg} / \mathrm{dl}$. This corresponds to a $\mathrm{kt} / \mathrm{V}$ of 1.11 using the Daugirdas equation. With a $\mathrm{V}$ of 40 liters, this is equivalent to a urea clearance of $30.8 \mathrm{ml} / \mathrm{min}$. The patient tolerated the treatment well. The catheters became infected and were removed. She expired of unremitting sepsis and cachexia about a month after the procedure. CFPD delivers excellent solute clearance and can be used in the ICU setting.

\section{3}

\section{CAPD in 20 Patients with Heart Failure and Chronic Renal Failure}

\author{
U. Teatini, L. Maltagliati, G.R. Longhena \\ Divisione Nefrologia e Dialisi, Bollate Hospital. Milano, \\ Italy
}

Many patients afflicted with renal failure are also suffering from heart failure. This retrospective study enrolled 20 (13 M/7 F) patients $(71.3 \pm 8.7 \mathrm{yrs})$ suffering from congestive heart failure (NYHA III and IV class) associated with Chronic Renal Failure (CRF). We treated these patients on PD and we evaluated survival, evolution of cardiac failure (NYHA class) and change of body weight. The follow-up was $22.1 \pm 17.9$ months. Cause of heart failure: ischemic cardiopathy in 13/20 and dilatative cardiomyopathy in 7/20. Cause of CRF: vascular disease 15; diabetes 3, ChGN 1, ChPN 1. Medical therapy: diuretics in 19/20, ACEi in $15 / 20$, digitalis in $6 / 20$. Serum creatinine was $5.85 \pm 1.4 \mathrm{mg} / \mathrm{dl}$; MAP 
$83 \pm 9 \mathrm{mmHg}$, EF $30 \pm 3 \%$. We can see the survival rate in the table:

\begin{tabular}{rccccccc}
\hline months & $\underline{0}$ & $\underline{6}$ & $\underline{12}$ & $\underline{18}$ & $\underline{24}$ & $\underline{30}$ & $\underline{36}$ \\
$\%$ & 100 & 85 & 60 & 50 & 40 & 30 & 20
\end{tabular}

NYHA class improved in 17/20; the decrease of body weight during follow-up was $6.3 \pm 3.5 \mathrm{Kgs}$. Hypertonic $(3.85 \%)$ bags every day were administred in 3 patients, one hypertonic bag in 13 patients and only isotonic bags in 4 patients. PD had to be discontinued in 2 patients because of peritonitis. Eleven patients died from sudden death (3); cardiac failure (2), cachexia (2), myocardial infarction (2), peritonitis (1), neoplasia (1). Conclusion: PD obtains a good survival rate in patients suffering from congestive heart failure associated with CRF and improves the quality of life through a decrease of NYHA class. Selection of patients remains difficult, and more precise criteria for starting therapy need to be defined.

\section{Liver Failure Therapy}

54

\section{Bilirubin Concentrations and Clearances during Extracorporeal Liver Support (ELS)}

\author{
A. Jung ${ }^{1,2}$, P. Krisper ${ }^{3}$, B. Haditsch ${ }^{3}$, R. Stauber ${ }^{4}$, \\ H. Holzer ${ }^{3}$ D. Schneditz ${ }^{1}$
}

${ }^{1}$ Department of Systems Physiology, ${ }^{3}$ Division of Nephrology \& Hemodialysis, ${ }^{4}$ Division of

Gastroenterology \& Hepatology, Medical University, Graz, AT,Austria ${ }^{2}$ Department of Medical Physics, AGH

University of Science \& Technology, Krakow, PL,Poland

Currently, the therapeutic effect of ELS therapy is judged by measuring changes in bilirubin concentration. However clearance gives more information about the efficiency of the process itself. The aim of this study was to compare bilirubin concentrations and clearances. Two different commercial systems (MARS (M), Teraklin, Germany; Prometheus (P), FMC, Germany) were used to analyze total, unconjugated, and conjugated bilirubin $(\mathrm{tB}, \mathrm{uB}, \mathrm{cB})$ in 8 acute-on-chronic liver failure patients. 32 consecutive treatments $(16 \mathrm{M}, 16 \mathrm{P})$ with the same flow rates were evaluated. Both in- and outflow bilirubin concentration were measured after $0.5,1,2,4$ and $6 \mathrm{~h}$ of ELS. Plasma clearance $(\mathrm{Cl})$ was calculated considering the effects caused by ultrafiltration $(\mathrm{UFR}): \mathrm{Cl}=($ cin - cout $) / \operatorname{cin} \times \mathrm{Qb} \times(1-\mathrm{hct})+\operatorname{cout} / \operatorname{cin} \times \mathrm{UFR}$. Pre-treatment values did not differ between $\mathrm{M}$ and $\mathrm{P}$ groups: $\mathrm{tB} 21.7 \mathrm{vs}$ $22.3 \mathrm{mg} / 100 \mathrm{~mL}$, uB 3.98 vs $4.18 \mathrm{mg} / 100 \mathrm{~mL}$ and $\mathrm{cB} 14.0 \mathrm{vs}$ $14.1 \mathrm{mg} / 100 \mathrm{~mL}$. Average clearances for $\mathrm{M}$ and $\mathrm{P}$ respectively were: $\mathrm{tB}$ $13.16 \pm 5.46$ vs $18.40 \pm 7.48, \mathrm{uB} 1.40 \pm 3.71$ vs $14.23 \pm 8.83$ and $\mathrm{cB}$ $16.45 \pm 6.89$ vs $20.41 \pm 5.71 \mathrm{~mL} / \mathrm{min}$. They differed between $\mathrm{M}$ and $\mathrm{P}$ $(\mathrm{p}<0.001)$. Clearances decreased during $\mathrm{M}$ and $\mathrm{P}$ treatments, only $\mathrm{uB}$ clearance remained constantly low during $\mathrm{M}$. All bilirubin concentrations significantly decreased during $\mathrm{M}$ and $\mathrm{P}$ treatment $(\mathrm{p}<0.0001)$, however stronger for $\mathrm{P}$ with the exception of $\mathrm{uB}$ in which increased in $\mathrm{M}(\mathrm{p}<0.05)$. There was no correlation between concentration and clearance, for $\mathrm{tB}\left(\mathrm{R}^{2}=0.1, \mathrm{p}<0.0001\right)$, $\mathrm{uB}\left(\mathrm{R}^{2}=0.02\right.$, n.s. $)$ and $\mathrm{cB}$ $\left(\mathrm{R}^{2}=0.1, \mathrm{p}<0.0001\right)$, indicating that the time course of concentrations is not sufficient to assess the efficiency of ELS.

55

\section{Suspected Acquired Lecithin Cholesterol Acyltransferase [LCAT] Deficiency in a Patient with End Stage Liver Cirrhosis and Renal Failure}

\author{
M. Wahba ${ }^{1}$, M. Sheaff ${ }^{3}$, J. Cross ${ }^{1}$, A. Burroughs ${ }^{2}$, \\ A. Burns ${ }^{1}$ \\ ${ }^{1}$ Department of Nephrology, ${ }^{2}$ Hepatology, Royal Free \\ Hospital, London, ${ }^{3}$ Department of Histopathology, \\ The London Hospital, London
}

A 54-year-old Caucasian man with end-stage Primary Biliary Cirrhosis (PBC) developed hepatorenal failure. Despite therapy with $20 \%$ HAS, Dopamine, Glypressin, NAC, and MARS neither his renal nor hepatic function improved. Liver biopsy confirmed end stage PBC. The initial renal biopsy report, from light microscopy, suggested membranous change. However, electron microscopy (EM) showed deposits of lipoidal material in the mesangium, sub-epithelial zone and intra-membranous areas, characteristic of Lecithin Cholesterol acyltransferase (LCAT) deficiency. Five weeks following admission the patient died following a large variceal bleed which precipitated grade IV encephalopathy. LCAT is a $63-\mathrm{kDa}$ glycoprotein enzyme, synthesized by the liver and involved in the synthesis of plasma cholesteryl esters and HDL-mediated cholesterol uptake from vascular tissue. Two categories of LCAT deficiency exist. The first is a rare group of inherited, autosomal recessive, conditions caused by a variety of well characterized mutations of the LCAT gene on chromosome16 q 22.1, with decreased plasma LCAT activity, corneal opacities, normocytic normochromic anemia, renal dysfunction with proteinuria and very low plasma HDL and HDL/Cholesterol ratios. The second or acquired forms of LCAT deficiency occur in conditions such as cholestatic liver disease where there is inadequate liver synthesis of LCAT or in nephrotic syndrome where LCAT may be lost in the urine. LCAT production is also known to be down-regulated in chronic renal failure. Our patient demonstrated the characteristic features of LCAT deficiency on renal biopsy. We postulate that he acquired LCAT deficiency secondary to his liver disease. This is a rare but recognized finding in patients with advanced liver disease who undergo renal biopsy. 


\section{6 \\ Development of Rally Administered Microcapsules to Degrade Non Protein Nitrogen (NPN) Compounds: Enabling the Gut to do the Work of the Kidney}

\author{
M.J. Lysaght, J.M. Bruder, J.A. O'Loughlin \\ Center for Biomedical Engineering, Brown University, \\ Providence, RI, USA
}

Therapies for uremia based upon diffusive and convective transport through man-made or natural membranes have reached a technological plateau. Advances in the past two decades have been limited to small refinements or altered delivery schedule. Our laboratory has been studying an alternative removal pathway in which orally delivered microcapsules are used to degrade NPN compounds during their transit in the intestinal tract. Such capsules can contain either enzymes directed at urea, creatinine, and uric acid or bacteria which have been genetically modified to produce these enzymes In situ. in-vitro experiments have confirmed that alginate is a suitable matrix material for these capsules, that solute removal is dose dependent, and that removal rates follow Michaelis-Menton kinetics. Short term in-vivo experiments have been conducted by administering various capsules to rodents with chemically induced acute renal failure. Orally administered microcapsules are capable of removing $70 \%$ of the urea and uric acid and $50 \%$ of the creatinine produced in the functionally anephric rodents over a 24 hour period. The presence of an anion exchange resin to scavenge ammonia ions was found necessary for effective removal of urea but not uric acid or creatinine. Bacteria and enzymes were biochemically equivalent in their depurative impact and the choice between the two would be based upon formulary considerations. Delivery of biochemically active capsules might lessen the frequency or duration of HD or CAPD, or might improve outcomes at existing therapy levels. In any case, it appears time for the community to take a fresh look at sorption and removal as an alternative to transport in the treatment of chronic uremia

\section{7 \\ Clinical Experience with MARS Therapy in Patients with Liver Failure Listed for Liver Transplantation}

\section{E. Rusu, D. Micu, S. Ioanitescu, M. Mihaila, D. Tulbure, I. Popescu, M. Voiculescu \\ Centre of Internal Medicine and Nephrology, Intensive Care Unit, and Centre of Liver Surgery and Transplantation, Fundeni Clinical Institute, Bucharest, Romania}

Background: The aim of the study is to assess the eficacy of Molecular Adsorbent Recirculating System (MARS) therapy in order to optimise the patients clinical and biological status and to create a bridge that allow patients survival until liver transplantation or retransplantation is available. Methods: Between January 2002 and April 2004 we studied 14 patients, 5 children and 11 adults, in whom
32 MARS treatment sessions were performed. Enrolled patients were divided in three groups: Acute Liver Failure (1 patient), Acute on Chronic Liver Failure (5 patients), Post Liver transplantation (8 patients). Before MARS procedure all patients presented severe cholestatic syndrome $($ mean bilirubin $=36.8 \mathrm{mg} / \mathrm{dl}$ ), decreased hepatic synthesis function (mean prothrombin activity $=51 \%$, mean albu$\min =2.76 \mathrm{~g} / \mathrm{dl}$ ), five of them had renal impairment. Eight patients presented hepatic encephalopathy grade II, five patients required mechanical ventilation. Six patients presented uncontrolled sepsis. Each patient received one to six treatments; the mean time/procedure was 12.1 hours (between 5 and 20 hours). Results: MARS therapy was well tolerated in all cases, with no major incidents. We have noticed favourable clinical effects: improvement in general condition, cognitive function, marked regression of jaundice and pruritus, improvement in renal function and hemodynamic status. Six patients had an unfavourable evolution with MSOF and death due to severe sepsis. We have obtained a significant reduction in total bilirubin level (mean 42.76\%), creatinine (mean 53.6\%), lactat (mean 47.1\%). Due to MARS treatment one patient was transplantated and one patient was retransplantated. Three patients are still alive and for eleven patients the survival increased with 23.5 days, which allows preparation for liver transplantation. Conclusion: We consider MARS therapy an efficient temporary solution for patients with liver failure listed for liver transplantation. The timing of initiation of the treatment and the management of infections are crucial for the MARS treatment success.

\section{8 \\ Detoxifying Capacity and Kinetics of the Prometheus System: Contribution of the Different Filters Inbuilt}

P. Evenepoel, A. Wilmer, F. Nevens, K. Claes, D. Kuypers,
B. Maes, W. Laleman, Y. Vanrenterghem

Department of Medicine, Division of Nephrology, Medical Intensive Care and Hepatology, University Hospital Leuven, Belgium

Background: Extracorporeal liver support therapies have been used for several decades as a bridging therapy prior to liver transplantation or as an addendum to standard medical therapy. The Prometheus system (Fresenius Medical Care AG, Bad Homburg, Germany) represents a cell-free, extracorporeal, liver assistance method for the removal of both albumin-bound and water-soluble endogenous toxins. The aim of the present study was to evaluate the removal capacity and selectivity of the different inbuilt dialysers and adsorption columns during a single $6 \mathrm{~h}$ treatment. Methods: Nine patients with acute-on-chronic liver failure were included (six females, age $49 \pm 4$ years). Levels of endogenous toxins (urea nitrogen [UN, mg/dL], creatinine [Cr, $\mathrm{mg} / \mathrm{dL}]$, total bilirubin $[\mathrm{tB}, \mathrm{mg} / \mathrm{dL}]$, and bile acids $[\mathrm{BA}, \mu \mathrm{mol} / \mathrm{L}]$ ) and albumin $[\mathrm{Alb}, \mathrm{g} / \mathrm{L}]$ were monitored in blood sampled at different sites (arterial line, venous line and between the absorbers and the high-flux dialyser) and at various time points (time $0,30,60,120,240$, and $360 \mathrm{~min}$ ). Concentrations were corrected for ultrafiltration. All data are represented as mean \pm SEM. Results: A significant decrease of the serum level of all toxins was observed (UN 108.7 \pm 23.2 vs $38.1 \pm 14.9$, Cr $2.4 \pm 0.7$ vs $1.2 \pm 0.3$, 
tB $31.1 \pm 4.1$ vs $17.0 \pm 1.6$, BA $155.7 \pm 32.5$ vs $66.0 \pm 15.4$; time 0 vs time 360 , signed rank rest, $\mathrm{p}<0.005$ all). The reduction rate of $\mathrm{UN}$, $\mathrm{Cr}$, tB and BA amounted to $69.1 \pm 4.8 \%, 47.8 \pm 5.0 \%, 42.2 \pm 4.7 \%$, and $58.5 \pm 6.0 \%$, respectively. Blood clearances [Cl, $\mathrm{mL} / \mathrm{min}]$ of all, but especially of the protein-bound toxins declined over time (Cl UN $170 \pm 4.3$ vs $142.9 \pm 16.8 ; \mathrm{Cl} \mathrm{Cr} 135.7 \pm 10.0$ vs $111.8 \pm 9.1 ; \mathrm{Cl}$ tB $29.3 \pm 5.1$ vs $13.7 \pm 3.7$; Cl BA $84.9 \pm 4.8$ vs $45.1 \pm 13.3$; time 30 vs time 360; Linear Mixed Models $\mathrm{p}<0.005$, all). Serum albumin levels decreased by $2.9 \pm 0.9 \mathrm{~g} / \mathrm{L}$ (signed rank test, $\mathrm{p}=0.055$ ). Not unexpectedly, $\mathrm{tB}$ was almost uniquely cleared by the adsorbers (UN $0.2 \pm 1.1, \mathrm{Cr} 6.9 \pm 5.7$, tB $92.3 \pm 4.2$, BA $62.9 \pm 3.9 \%$ of total $\mathrm{Cl}$ ). Conclusion: Both albumin-bound and water-soluble toxins are adequately removed by the Prometheus system. Our data suggest that the rate and efficacy of removal of albumin-bound toxins is related to both the strength of the albumin binding and the saturation of the adsorption columns. Limited losses of albumin occur during treatment with the Prometheus system.

59

\section{Therapeutic Application of Molecular Adsorbents Recirculating System (MARS) in Various Pathogenic SIRS/MODS Patients}

\author{
H.-T. LuO', L.-M. GuO ${ }^{2}$, M. Wu ${ }^{3}$ \\ ${ }^{1}$ Department of Infectious Diseases, ${ }^{3}$ ITU \& Blood \\ Purification Center, the First People's Hospital of \\ Foshan, Guangdong, ${ }^{2}$ ICU \& Artificial Liver Support \\ Center, Beijing DiTan Hospital, Beijing, P.R. China
}

Introduction: It has been widely accepted that nitro oxide (NO) and cytokines play important roles in the development of multiple organ dysfunction (MODS). The aim of this study was to assess the effectiveness of MARS to remove NO and cytokines in patients with MODS. Materials and Methods: 110 single MARS treatments were performed with length of 6-24 hours on 39 MODS patients $(27 \mathrm{M} / 12 \mathrm{~F})$, mean age 50 (range from 18-80). The MARS system was used with a continuous venovenous hemofiltration (CVVH) machine, for 8-24h. Results: The MARS therapy was associated with a significant removal of NO $(58.0 \pm 22.9$ vs $25.2 \pm 19.0 \mathrm{umol} / \mathrm{l}), \mathrm{TNF}-\alpha(4.83 \pm 2.6$ vs $1.70 \pm 1.25 \mathrm{ug} / \mathrm{l}), \mathrm{IL}-2$ $(6.35 \pm 2.13$ vs $4.25 \pm 1.13 \mathrm{ng} / \mathrm{l})$, IL-6 (394.9 \pm 134.5 vs $108.0 \pm$ $117.3 \mathrm{pg} / \mathrm{ml})$, IL-8 $(1.20 \pm 0.63$ vs $0.52 \pm 0.15 \mathrm{ng} / \mathrm{ml})$, all $\mathrm{p}<0.01$. In addition there were marked reductions of other non-water soluble albumin bound toxins and water soluble toxins, these were associated with a improvement of the patients' clinical conditions including hepatic encephalopathy, deranged hemodynamic situation and as well as renal and respiratory function, thus resulted into marked decrease of Sequential Organ Failure Assessment (SOFA) score and improved outcome $(8.97 \pm 1.78$ vs $5.87 \pm 3.14)$. 16 patients were able to be discharged from the hospital or bridged to successful liver transplantation, the overall survival of 39 patients was $41 \%$. We confirmed that this newer liver support strategy would be applicable to enhance the native recovery process or prepare patients for transplantation with limiting complications and organ system dysfunction for the critically ill patients with various underlying diseases.

22nd Annual Meeting of the International

Society of Blood Purification (ISBP)
60

\section{Molecular Adsorbents Recirculating System: Clinical Experience in Patients with Acute and Acute on Chronic Liver Failure}

L.-M. Chen, X.-O. Ding, J.-Z. Zou, Y. Fang, Y.-H. Zhong,

S.-W. Xu, C.-S. Fu, M. Yuan, J. Teng, J. Ji

Department of Nephrology, Shanghai Zhongshan

Hospital, Fudan University, China

Introduction: The aim of this study is to evaluate the effect of treatment with the Molecular Adsorbents Recirculating System (MARS) in liver failure patients. Materials and Methods: In 28 patients (median age, 50.57 years), 12 cases were acute liver failure and 16 cases of acute on chronic liver failure. The 56 times of $6-8$ hour MARS intermittent treatments were performed without any major adverse events. Results: Significant decreases in serum total bilirubin $(31.7 \%)$, conjugated bilirubin $(29.15 \%)$, bile acid $(35.91 \%)$ and ammonia $(53.68 \%)$ were observed $(p<0.01)$, single treatment contributed to the markedly improvement of coagulapathy (PT decreased from $32.37 \pm 9.96$ seconds to $21.82 \pm 10.39$ seconds, $\mathrm{P}<0.01$ ), most patients $(24 / 28,85.7 \%)$ achieved a remarkable symptomatic recovery after the single treatment. The 30 days hospital survival rate for the 28 liver failure patients was $71.4 \%$ (20/28): 2 patients of acute liver failure recovered, 8 cases of acute on chronic liver failure improved and discharged, 10 patients were successfully bridged to liver transplantation, 8 cases died of multiorgan failure. Conclusion: It is concluded that MARS method can be served as an optimistic treatment for liver failure patients with improved immediate survival rate and inspiring bridging support to liver transplantation.

61

\section{Application of Molecular Adsorbents Recirculating System (MARS) in Patients with Severe Chronic Viral Hepatitis B in Middle and End Stages}

\author{
L.-Y. Liu' ${ }^{1}$, H. Deng ${ }^{1}$, X.-J. Sun', J. Zhao' ${ }^{1}$, X.-Y. Li ${ }^{1}$, \\ M.-M. Wang ${ }^{2}$ \\ ${ }^{1}$ Department of Infectious Diseases, Second Hospital of \\ Xi'an, JiaoTong University, China, ${ }^{2}$ Therapeutic Blood \\ Purification Research Center, University of Rostock, \\ Germany
}

Objective: To evaluate the therapeutic effects of MARS in treating patients with severe chronic viral hepatitis $\mathrm{B}(\mathrm{SCH}-\mathrm{B})$ in middle and end stages. Methods: 16 patients with $\mathrm{SCH}-\mathrm{B}$ in middle and end stages underwent 6 to $8 \mathrm{~h}$ MARS therapy as the MARS group, retrospectively reviewing of 16 patients chosen from previous therapy data also of SCH-B clinically matched to the MARS group were regarded as the Standard Medical Therapy (SMT) group, who had been treated with conventional methods except MARS. Results: The single MARS treatment contributed to significant decreases on levels of serum total bilirubin (from $547 \pm 187 \mathrm{mmol} / \mathrm{L}$ to 
$312 \pm 118 \mathrm{mmol} / \mathrm{L}, \mathrm{p}<0.05)$ and non-conjugated bilirubin $(379 \pm$ $134 \mathrm{mmol} / \mathrm{L}$ to $185 \pm 68 \mathrm{mmol} / \mathrm{L}, \mathrm{p}<0.05)$, meanwhile, MAP increased from $72 \pm 8 \mathrm{mmHg}$ to $81 \pm 7 \mathrm{mmHg}(\mathrm{p}<0.05)$. There were statistical survival differences between two groups, in SMT group, 6 of 12 patients in middle stage survived (50\%), while in MARS group the survival for comparable middle stage patients was 10/12 (83.3); for the end stage subgroup comparison, all 4 patients died in SMT group, but the MARS therapy improved the survival to $25 \%(1 / 4)$ in it's 4 patients. The overall survival of these two groups with middle and end stage SCH-B patients were SMT of $37.5 \%$, MARS of $68.5 \%(p<0.05)$. Conclusions: The MARS therapy effectively removed serum bilirubin and other albumin bound toxins, increased the MAP, application of MARS significant improve the survival of severe chronic viral hepatitis in middle and end stages.

62

\section{Artificial Liver Support MARS Therapy as a Bridge to Re-Transplantation in Two Cases on Long Anhepatic Duration}

\author{
Y.-H. Liu' ${ }^{1}$, Y. Wang ${ }^{1}$, L.-X. Y Y ${ }^{1}$, L.-Y. Sun ${ }^{1}$, B.-L. Feng ${ }^{1}$, \\ Z.-Y. Shen ${ }^{1}$, M.-M. Wang ${ }^{2}$ \\ ${ }^{1}$ Tianjin Organ Transplantation Institute, Tianjin First \\ Central Hospital, China, ${ }^{2}$ Visiting Research Fellow, \\ Therapeutic Blood Purification Research Center, \\ University of Rostock, Germany
}

Introduction: Liver transplantation remains the treatment for many patients with end stage liver disease. We report our experience on successful bridging of two anhepatic cases for 26 and 17 hours prior to re-transplantation with MARS therapy. Materials and Methods: Case 1. A 36 years old man underwent liver transplantation but the implanted donor liver had primary non function (PNF) and was resected. A portal-cava shunt was made and plasma exchange started, but he became hypotensive. Thus MARS therapy was initiated, which was well tolerated, and his anhepatic condition was under stable control during 11 hours of MARS treatment, and after 26 hours of anhepatic phase, he was successfully re-transplantation. Case 2. A 48 yr old man underwent urgent LTx for acute on chronic hepatic failure, again PNF developed during the operation, and MARS therapy was started after the transplanted liver was removed. 10 hours of MARS treatment improved mean arterial blood pressure (pre $50 \mathrm{mmHg}$ vs 77 post), despite $>50 \%$ reduction in Dopamine and Noradrenaline. He was successfully bridged for 17 hours anhepatic phase until successfully re-transplantation. Conclusion: Our report of these two anhepatic cases prove that MARS artificial liver can be of an effective support method for long time bridging PNF until available re-transplantation.
63

Experience with Molecular Adsorbents Recirculating System (MARS): China Results on Hepatitis $B$ Induced Liver Failure
M.-M. Wang ${ }^{1}$, O.-F. Ye ${ }^{2}$, Y.-J. Yang ${ }^{3}$, S.-B. Chen ${ }^{4}$, X.-M. Zhou ${ }^{5}$, L.-M. Guo ${ }^{6}$, X.-B. Hu
${ }^{1}$ Therapeutic Blood Purification Research Center, University of Rostock, Germany, ${ }^{2}$ Hunan Transplantation Medical Center, Central South University,
${ }^{3}$ Department of Artificial Liver Therapy, Nanjing No.2 People's Hospital, South-East University Medical College, ${ }^{4}$ Division of Infectious Diseases, Department of Medicine, the First Affiliated Hospital of Jiangxi Medical College, ${ }^{5}$ Institute of Digestive Diseases, Xi'jing Hospital, Fourth Military Medical University, ${ }^{6}$ ICU \& Artificial Liver Support Center, Beijing DiTan Hospital, ${ }^{7}$ Department of Severe Liver Diseases, Guangzhou No.8 Hospital, China

Introduction: Since 2001, more than 500 patients have been treated in different centers in China with MARS. Methods: Review of 347 MARS treatments in 149 patients with HBV liver failure (overlapping HCV or HDV included), classified into 3 groups (acuteALF, subacute-SALF and chronic-AoCLF), and SALF and AoCLF were furthermore classified into Early, Middle and End. The mean age was $44.3 \pm 13.2$ y (range from 15-80), $102 \mathrm{M}$, with average of 2.33 MARS treatments/patient. Results: MARS treatments were associated with a significant reduction of albumin bound toxins and various cytokines, as well as the water-soluble toxins. Most patients showed positive response to the therapy, with increases in PTA and MAP, and significant decrease in HE grade and CTP index. 84 patients survived in hospital (56.4\%), including 9 following liver transplantation, 18 patients were successfully bridged to liver transplantation. Survival of the ALF, SALF and AoCLF patients were $62.5 \%, 66.7 \%$ and $54.5 \%$, AoCLF patients formed the majority $(121 / 149-81.2 \%)$. Patients in End-stage presented the largest among subgroup of SALF and AoCLF (69/133, 51.9\%), patients in Early and Middle stages gained more favorable outcomes than those in End stage $(91.7 \%$ and $75 \%$ vs $30.8 \%)$. In hospital survival for the ASH and SSH patients were $62.5 \%$ and $66.7 \%$ respectively. It was observed that $\mathrm{CSH}$ patients formed the majority part (121 patients-81.2\%) among all 149 patients, and patients in end stage presented the largest in subgroup of CSH $(65 / 121,53.7 \%)$, however, patients in early and middle stages gained more favorable outcome than those in end stage (92.3\% and $73.7 \%$ vs $31.9 \%$ ). Large randomized controlled studies in China are desirable to verify the appropriate intervention of MARS in right indications and right phase of hepatic failure so as to be benefited with optimal therapeutic results. 


\section{4 \\ Preoperation Risk Factor Analysis in Orthotopic Liver Transplantation with Pretransplant Artificial Liver Support Therapy}

Q.-F. Ye1, J.-Z. Yuan', Y.-Z. Ming ${ }^{1}$, L.-S. Zhong, M.-M. Wang ${ }^{2}$, S.-H. Zhu ${ }^{1}$, K. Wu $u^{1}$, M.-Z. Zhang

${ }^{1}$ Hunan Transplantation Medical Center, Central South University, China, ${ }^{2}$ Therapeutic Blood Purification

Research Center, University of Rostock, Germany

Introduction: The early mortality after OLT remains relatively high, we evaluate the pretransplantation MARS (Molecular Adsorbents Recirculating System) therapy in reducing the relevant risk factors relating to this early mortality. Methods: 50 adult patients undergoing OLT with MARS preoperation therapy were studied, 28 men and 22 women with a mean age of 52.24 (range 46-68) years. Results: 80 treatments were performed safely, all patients showed positive response, Cr, SOFA, GCS, MAP, TNF- $\alpha$ and IL-10 were improved significantly (Table 1), 8 patients recovered and avoided OLT, 8 patients died, 34 patients were successfully bridged to OLT: the OLT outcome within 30 days was: 28 kept alive and 6 patient died. The stepwise logistic regression indicated reversible factors that had independent associations with early mortality were $\mathrm{Cr}$, INR, SOFA, TNF- $\alpha$ and IL-10, with regression coefficients of $0.315,0.309,0.224,0.192$ and 0.188 , respectively. Conclusion: We think preoperation SOFA, $\mathrm{Cr}$, INR, TNF- $\alpha$ and IL-10 are the main OLT preoperative reversible risk factors, MARS treatment before OLT can relieve these factors significantly, hence improve survival rate of OLT or even avoid transplantation.

Table 1. Comparison of clinical and biochemical data pre- and postMARS treatment

\begin{tabular}{lccc}
\hline Parameter & Pre-treatment & Post-treatment & P value \\
\hline Prognostic scores & & & \\
SOFA score (points) & $9.72 \pm 1.89$ & $6.98 \pm 2.34$ & $<0.01$ \\
Glasgow coma & $7.23 \pm 1.21$ & $13.34 \pm 2.33$ & $<0.01$ \\
$\quad$ score (points) & & & \\
Clinical and biochemical & & & \\
$\quad$ parameters & $70.5 \pm 12.1$ & $85.1 \pm 10.4$ & $<0.001$ \\
MAP (mmHg) & $2.83 \pm 1.7$ & $1.80 \pm 1.39$ & $<0.01$ \\
TNF- $\alpha(\mathrm{Pg} / \mathrm{ml})$ & $7.80 \pm 6.0$ & $4.5 \pm 4.5$ & $<0.05$ \\
IL-10 (Pg/ml) & $295.7 \pm 1,125.4$ & $237.14 \pm 91.82$ & $<0.05$ \\
ALT & $341.16 \pm 94.93$ & $232.74 \pm 169.29$ & $<0.05$ \\
TBIL (umol/L) & $162 \pm 104$ & $73 \pm 51$ & $<0.001$ \\
TBA (mmol/L) & $35.5 \pm 35.7$ & $35.7 \pm 6.8$ & $>0.05$ \\
Albumin (g/L) & $4.66 \pm 3.35$ & $3.98 \pm 3.16$ & $>0.05$ \\
INR & $128.67 \pm 87.73$ & $33.21 \pm 22.26$ & $<0.05$ \\
Cr (umol/L) & $151.31 \pm 88.99$ & $28.28 \pm 20.19$ & $<0.05$ \\
Ammonia (mmol/L) & & & \\
\hline
\end{tabular}


Açikel, Ü. 24, 25

Agin, H. 25

Aires, I. 1

Akiba, T. 6, 27

Algin, I. 25

Alquist, M. 10

Al-Rohani, M. 29

Amerling, R. 22, 52

Antoniadi, G. 47

Antonov, S. 15, 16

Audzijoniene, J. 11

Avramovic, M. 48

Bak, M. 25

Balciunas, M. 11

Baldin, C. 7

Bammens, B. 2

Banerjee, A. 34

Beerenhout, C. 5

Belechri, A.-M. 44

Bergamo, D. 26

Bermond, F. 26

Berta, K. 45

Bondi, M. 12

Bosselmann, H.-P. 51

Brand, A. 4

Bruder, J.M. 56

Bucsa, C. 39, 40

Burdese, M. 26, 32

Burns, A. 34, 55

Burroughs, A. 55

Calabrese, G. 7

Calkavur, S. 25

Canaud, B. 3, 4

Cappelli, G. 12

Chalabi, L. 4

Chan, C.-K. 50

Chen, L.-M. 60

Chen, S.-B. 63

Chow, V. 50

Claes, K. 58

Clark, W. 14

Coen, G. 18

Collins, G. 3
Consiglio, V. 26, 32

Cross, J. 55

Curran, S.P. 17

Daly, C. 13

Das, S. 38

Davenport, A. 51

Davies, S.J. 51

Deng, H. 61

Dheu, C. 9

Di Felice, A. 12

Ding, X.-Q. 60

Donovan, K. 51

Dubrow, A. 22, 52

Dukova, P. 15

Eleftheriadis, T. 47

Errico, R. 46

Evenepoel, P. 2, 58

Falkenhagen, D. 45

Falkenhain, S. 4

Fang, Y. 60

Feng, B.-L. 62

Ferreira, A. 1

Fertolani, D. 12

Filho, J.C.D. 51

Fischbach, M. 9

Fleva, A. 20, 43, 49

Fop, F. 26

Formet, C. 3

Fu, C.-S. 60

Gai, M. 32

Galice, E. 39, 40

Gassensmith, C. 14

Georgiev, M. 15, 16

Giannakou, A. 20

Gil, C. 1

Ginikopoulou, E. 20, 43, 49

Gonella, M. 7

Griskevicius, A. 11
Griveas, I. 20, 43, 49

Guo, L.-M. 59, 63

Haditsch, B. 54

Harrami, L. 3

Haveson, S. 22

Heimburger, O. 51

Helms, P. 9

Hidai, H. 31

Holzer, H. 54

Hossain, R.M. 38

Hu, X.-B. 63

Iliescu, O. 39

Ioanitescu, S. 57

Ionescu, C. 39, 40

Iqbal, M. 38

Ishimori, I. 6

Ishimura, E. 41

Islam, M.N. 38

Islam, M.S. 38

Ismail, G. 39, 40

Jeantet, A. 32

Jeffery, S. 46

Ji, J. 60

Johansson, A.C. 51

Jorge, C. 1

Jung, A. 54

Juszczak, M. 34

Kakasi, E. 47

Kalidas, K. 46

Kalovoulos, M. 44

Kanaa, M. 37

Karabay, Ö. 23, 24, 25

Kenda, R.B. 21

Keogh, J.A.B. 17

Kesse-Adu, R. 34

Kimata, N. 27

Kirijakov, Z. 16

Kishimoto, T. 30

Koike, T. 28

\section{KARGER}

Fax +4161306 1234

E-Mail karger@karger.ch

www.karger.com 
Kooman, J. 5

Kortsaris, A. 47

Krieter, D.H. 3, 4, 42

Krisper, P. 54

Kubota, M. 28

Kumano, N. 28

Kurachi, T. 28

Kuypers, D. 58

Kyriklidou, P. 20, 43, 49

Laleman, W. 58

Lang, S.M. 8

Laugel, V. 9

Lemke, H.-D. 3, 4, 42

Leunissen, K. 5

Lewis, R. 33

Li, X.-Y. 61

Liakopoulos, V. 47

Ligabue, G. 12

Lindley, E. 37

Liu, L.-Y. 61

Liu, Y.-H. 62

Lixandru, M. 40

Lo, S.H.-K. 50

Longhena, G.R. 53

Losito, A. 46

Luik, A. 5

Luo, H.-T. 59

Lysaght, M.J. 56

MacLeod, A. 13

Maddalena, E. 32

Maes, B. 58

Maffei, S. 26

Major, L. 45

Malostovker, I. 22, 52

Maltagliati, L. 53

Mangiarotti, G. 26

Manou, E. 20, 43, 49

Mansur, M.A. 38

Marin, S. 40

Martina, G. 26, 32

Masuda, T. 6

Matias, P. 1

Matsuyama, M. 19

Mayo, P. 52

Meimaridou, D. 20, 43, 49

Mellotte, G.J. 17

Memmos, D. 44

Mezza, E. 26, 32

Micu, D. 57

Mihaila, M. 57

Mineshima, M. 6
Ming, Y.-Z. 64

Mitsopoulos, E. 20, 43, 49

Mo, S.K.-L. 50

Mochizuki, T. 27

Mohsin, M. 38

Moragues, H.L. 3

Morris, P.J. 378 (K)

Morgenroth, A. 42

Motta, D. 32

Nagai, K. 27

Naganuma, T. 19

Nakatani, T. 19, 30

Nevens, F. 58

Nishizawa, Y. 41

O’Loughlin, J.A. 56

O’Neill, J. 14

Oleru, C. 52

Önol, H. 23, 24

Opatrny K., Jr. 35, 36

Pacitti, A. 26

Paganini, E. 14

Papadopoulou, D. 20, 43, 49

Papagianni, A. 44

Passlick-Deetjen, J. 45

Pavlitou, A. 20, 43, 49

Perrone, S. 12

Piccoli, G.B. 26, 32

Plum, J. 51

Polanska, K. 36

Ponikvar, J.B. 21

Ponikvar, R. 21

Popescu, I. 57

Pratesi, G. 7

Rabindranath, K.S. 13

Rahman, H. 38

Ricardi, M. 12

Roderick, P. 13

Rokyta, R., Jr. 36

Rosati, M. 12

Rosero, H. 22

Rus, R.R. 21

Rusu, E. 57

Sakai, Y. 28

Sakellariou, G. 20, 43, 49
Santoni, S. 46

Sato, Y. 6

Sauer, N. 4, 42

Schiffl, H. 8

Schneditz, D. 54

Sefrna, F. 35

Segoloni, G.P. 26, 32

Sheaff, M. 55

Shen, Z.-Y. 62

Shum, H.-P. 50

Silistreli, E. 24, 25

Simonsen, O. 51

Soragna, G. 32

Stauber, R. 54

Stefanidis, I. 47

Stefanovic, V. 48

Strippoli, G.F.M. 13

Sugimura, K. 19, 30

Summerton, J. 3

Sun, L.-Y. 62

Sun, X.-J. 61

Sundaram, S. 52

Sunohara, T. 6

Tabata, T. 41

Takahashi, H. 28

Takemoto, Y. 19, 30

Tan, J. 33

Tanabe, K. 27

Taniwaki, H. 41

Tattoli, F. 32

Taylor, D. 14

Teatini, U. 53

Teng, J. 60

Tetta, C. 12

Tokumoto, T. 27

Toma, H. 27

Tranaeus, A. 51

Tsuchida, K. 19, 30

Tulbure, D. 57

van der Sande, F. 5

Vanrenterghem, Y. 2, 58

Vargemezis, V. 47

Vaslaki, L.R. 45

Vayonas, G. 47

Velickovic, R. 48

Verbeke, K. 2

Visvardis, G. 20, 43, 49

Vit, L. 35, 36

Voiculescu, M. 39, 40, 57 
Wahba, M. 55

Wallace, S.A. 13

Wang, M.-M. 61, 62, 63, 64

Wang, Y. 62

Wanner, C. 4, 42

Watanabe, E. 27

Webb, A. 33

Weber, C. 45

Weber, V. 45

Weinstein, D. 14

Will, E. 37

Williams, P. 51

Wilmer, A. 58

Wingren, K. 10

Wojke, R. 45
Wong, K.-S. 50

Woodrow, G. 51

Wright, M. 37

Wu, K. 64

Wu, M. 59

Xu, S.-W. 60

Yamashita, Y. 27

Yang, Y.-J. 63

Ye, Q.-F. 63, 64

Yetkin, U. 23, 24

Yonova, D. 15, 16
Yoshimura, R. 19

Yu, L.-X. 62

Yuan, J.-Z. 64

Yuan, M. 60

Yurekli, I. 25

Zemanova, P. 35

Zhang, M.-Z. 64

Zhao, J. 61

Zhong, L.-S. 64

Zhong, Y.-H. 60

Zhou, X.-M. 63

Zhu, S.-H. 64

Zou, J.-Z. 60 